Volume 111, Number 1, January-February 2006

Journal of Research of the National Institute of Standards and Technology

[J. Res. Natl. Inst. Stand. Technol. 111, 9-30 (2006)]

\title{
A Summary of Lightpipe Radiation Thermometry Research at NIST
}

\section{Benjamin K. Tsai}

National Institute of Standards and Technology, Gaithersburg MD 20899-8441

benjamin.tsai@nist.gov

\author{
During the last 10 years, research in light- \\ pipe radiation thermometry has signifi- \\ cantly reduced the uncertainties for tem- \\ perature measurements in semiconductor \\ processing. The National Institute of \\ Standards and Technology (NIST) has \\ improved the calibration of lightpipe radi- \\ ation thermometers (LPRTs), the charac- \\ terization procedures for LPRTs, the in situ \\ calibration of LPRTs using thin-film ther- \\ mocouple (TFTC) test wafers, and the \\ application of model-based corrections to \\ improve LPRT spectral radiance tempera- \\ tures. Collaboration with industry on \\ implementing techniques and ideas estab- \\ lished at NIST has led to improvements in \\ temperature measurements in semiconduc- \\ tor processing. LPRTs have been success- \\ fully calibrated at NIST for rapid thermal \\ processing (RTP) applications using a \\ sodium heat-pipe blackbody between \\ $700{ }^{\circ} \mathrm{C}$ and $900{ }^{\circ} \mathrm{C}$ with an uncertainty of \\ about $0.3{ }^{\circ} \mathrm{C}(k=1)$ traceable to the \\ International Temperature Scale of 1990.
}

\begin{abstract}
Employing appropriate effective emissivity models, LPRTs have been used to determine the wafer temperature in the NIST RTP Test Bed with an uncertainty of $3.5^{\circ} \mathrm{C}$. Using a TFTC wafer for calibration, the LPRT can measure the wafer temperature in the NIST RTP Test Bed with an uncertainty of $2.3^{\circ} \mathrm{C}$. Collaborations with industry in characterizing and calibrating LPRTs will be summarized, and future directions for LPRT research will be discussed.
\end{abstract}

Key words: blackbody; effective emissivity models; heat-pipe blackbody; lightpipe radiation thermometer; radiation thermometer; temperature; thin-film thermocouple; traceability; uncertainty.

Accepted: December 2, 2005

Available online: http://www.nist.gov/jres

\section{Background}

Recently, many advances have been made in semiconductor metrology, as evidenced by the goal in the International Technology Roadmap for Semiconductors (ITRS) to achieve $45 \mathrm{~nm}$ dynamic random access memory (DRAM) 1/2 pitch by 2010 [1]. An important growing sector of this industry has been the rapid thermal processing (RTP) for chemical vapor deposition, physical vapor deposition, oxidation, annealing, silicidation, and oxide-etch processes. Compared to the traditional batch processing of silicon wafers, singlewafer RTP offers advantages of higher ramp rates, shorter processing times, tighter ambient control, and shorter cycle times.

Accurate temperature measurement and control during RTP by using noncontact techniques such as lightpipe radiation thermometers (LPRTs) is crucial for achieving high throughput and maintaining quality. However, achieving accurate traceable temperature measurements by using noncontact LPRTs has been challenging. First, stray light from the source bouncing off reflective surfaces can provide extraneous unwanted signal into the radiometer. Second, temperature variations with time and with wafer location can complicate the measurement process and can increase the 
uncertainty in the measurements. Third, LPRT temperature measurements can be affected by changes in the wafer's optical properties, which can vary with temperature, wavelength, wafer location, surface topography, and chemical composition. Fourth, the effective emissivity of the wafer and surroundings, which accounts for interreflections with other surfaces in the radiation chamber, is highly dependent on the geometry and radiative properties of these surfaces. Finally, establishing traceability for LPRT measurements is a nontrivial and significant investment in time and effort.

Implicit in the mission of the National Institute of Standards and Technology (NIST) [2] and of our RTP temperature project is the task of developing high-quality measurement standards and establishing a calibration system whereby users can derive their temperature traceability. To this end, we are committed to establishing a national protocol for calibration of LPRTs using stable blackbodies in the temperature range of $700{ }^{\circ} \mathrm{C}$ to $1000^{\circ} \mathrm{C}$ traceable to the International Temperature Scale of 1990 (ITS-90) [3].

In the early 1980s at the National Bureau of Standards (now NIST), a fiber-optic lightpipe (LP) coupled to a radiation detector was first used as a thermometer to measure the temperature of gases. The fiber tip exposed to the hot gases was coated with opaque, black films of platinum or rhodium [4-6] to form a cavity, which emitted near-blackbody radiation that was transferred to the radiation detector. In the early 1990s, the ripple technique [7] for RTP applications used rodtype LPs as transfer optics to collect and transfer spectral radiance from wafer targets onto the radiation detector. Since that time, the LPRT has been used to monitor wafer temperature in high-temperature semiconductor processing, because of its minimal thermal disturbance to the heated wafer and the radiation field, and because of the convenience of its noncontact measurement capability [8]. LPRTs are presently used for temperature measurement in rapid thermal annealing, rapid thermal oxidation [9], and rapid thermal chemical vapor deposition [10], as well as for emissivity determinations [11].

During this past decade, NIST has led the effort in assisting industry to characterize the performance of industrial LPRTs, gain an increased understanding of the importance of traceability to a national standard, and develop a greater appreciation for the need for accuracy. Accordingly, the NIST RTP Temperature Project set a goal of achieving $2{ }^{\circ} \mathrm{C}$ measurement uncertainty at $1000{ }^{\circ} \mathrm{C}$ in temperature accuracy, as outlined in the Semiconductor Industry Association roadmap [1]. This low uncertainty has been accom- plished through the four-pronged approach of the NIST RTP temperature project: (1) develop procedures to fabricate and calibrate thin-film thermocouple (TFTC) wafers for in situ calibration of the LPRT against a thinfilm thermocouple test wafer [12-31]; (2) characterize LPRTs [32-37,79]; (3) develop analytical models to predict the corrections to spectral radiance temperatures using an LPRT calibrated against a blackbody [38-52]; and (4) collaborate with equipment, device, and instrument manufacturers in implementing new methods for reliable and traceable temperature measurements [53-57]. As a result of this effort, in the last ten years at NIST, we have achieved several significant milestones in our noncontact temperature research with LPRTs: (1) calibration of LPRTs using the sodium heatpipe blackbody (Na-HPBB) with an uncertainty of $0.2^{\circ} \mathrm{C}(k=1)$ [29]; (2) temperature measurement using LPRTs and effective emissivity models, resulting in an uncertainty of $3.5^{\circ} \mathrm{C}$ [29]; (3) in situ calibration of a LPRT using a thin-film thermocouple wafer with an uncertainty of $2.1^{\circ} \mathrm{C}$ [29]; (4) qualitative and quantitative optical visualization techniques for evaluating and inspecting sapphire lightpipes [35]; and (5) recommendations for making more accurate temperature measurements using LPRTs [34]. While the work has specifically addressed a semiconductor application, the approaches have general applicability for achieving reliable, traceable temperature measurements using LPRTs in other material processing and manufacturing environments, such as those used in the production of steel, aluminum, and glass.

The purposes of this paper are to document in one place all LPRT work done at NIST in the past decade, reference all NIST papers published about LPRT research, and report on the state of the art in LPRT research. This paper will summarize the types of LPRTs, their calibration and characterization techniques, in situ calibration of LPRTs using TFTCs, and model-based corrections of LPRT measurements. Finally, potential future work in LPRT research is discussed.

\section{Radiation Thermometers and LPRTs}

Traditionally, lightpipe (LP) sensors are attractive in temperature monitoring applications for at least five reasons. First, the noncontact and nondestructive nature of LPs does not alter or destroy the original surface. Second, LPs provide immunity from shock, vibration, and other adverse environments, such as chemical, thermal, and electromagnetic interference. Third, LPs 
are very convenient especially in confined areas and can be placed very close to a target if desired. Fourth, LPs are safe even in high voltage areas and in ionizing plasma fields. Fifth, high numerical apertures in LPs can reduce significantly the effects of the variability in optical properties [55].

LPRTs, such as the one in Fig. 1a, typically consists of a high-quality sapphire crystal rod (LP) enclosed in a concentric sapphire sheath and linked by flexible quartz fibers to a silicon detector with a near-infrared filter. Besides the detector, the control box contains the front panel display and the optics and electronics necessary to digitize the measured signal and to convert it into the appropriate radiance temperature. The sapphire rod is enclosed in a concentric sapphire sheath for protection from shock and vibration. The LPs used in our studies are of varying lengths, but they are all approximately $2 \mathrm{~mm}$ in diameter. The sapphire sheath that surrounds the LP has a typical outer diameter of approximately $4 \mathrm{~mm}$. In normal operation for measuring the radiance temperature, the LPs are connected to a $1 \mathrm{~mm}$ diameter quartz fiber-optic cable. From now on, LPs will refer only to the crystal rod and sheath, while LPRTs will refer to the complete system including the LP rod and sheath, fiber-optic cable, optics, electronics, and all other necessary accessories (excluding the computer and data acquisition system) for measurement of the radiance temperature.

Spot-type radiation thermometers (STRTs) are also becoming common as temperature sensors in RTP applications, especially in areas where it is not possible or feasible to place the LP close to the wafer but there is adequate optical access to the wafer spot. To view the wafer spot, the STRT must have a sufficiently small field-of-view and spot size. A STRT, like the one in Fig. 1b, usually consists of the lens, optics, electronics, eyepiece, and the front panel display. STRTs have been calibrated and researched at NIST. American Society for Testing and Materials (ASTM) standards have been developed for STRTs [56-57], and numerous studies of STRTs have been published [4-8,12,55,58-66].

Cableless lightpipe radiation thermometers (CLRTs) are a new generation of LPRTs, which have all of the attractive features of LPRTs. In addition, the elimination of the flexible cable reduces the measurement uncertainty by at least $2{ }^{\circ} \mathrm{C}$. The replacement of the controller box with the lightweight controller capsule saves space. Like the LPRTs, the CLRTs also include a sapphire lightpipe enclosed in a concentric sapphire sheath (see Fig. 1c). In addition, CLRTs are accompanied by software for reading and acquiring the temperature and signal data and contain a small electronics controller cylinder which houses the optics and electronics. Disadvantages of CLRTs include the shorter lengths and the inflexibility of the cables.

\section{Calibration of LPRTs}

\subsection{Standard Reference Blackbody Source}

At NIST, LPRTs, STRTs, CLRTs, and other types of RTs, are routinely calibrated against a sodium heat pipe blackbody (Na-HPBB). The main Inconel ${ }^{1}$ cavity of the
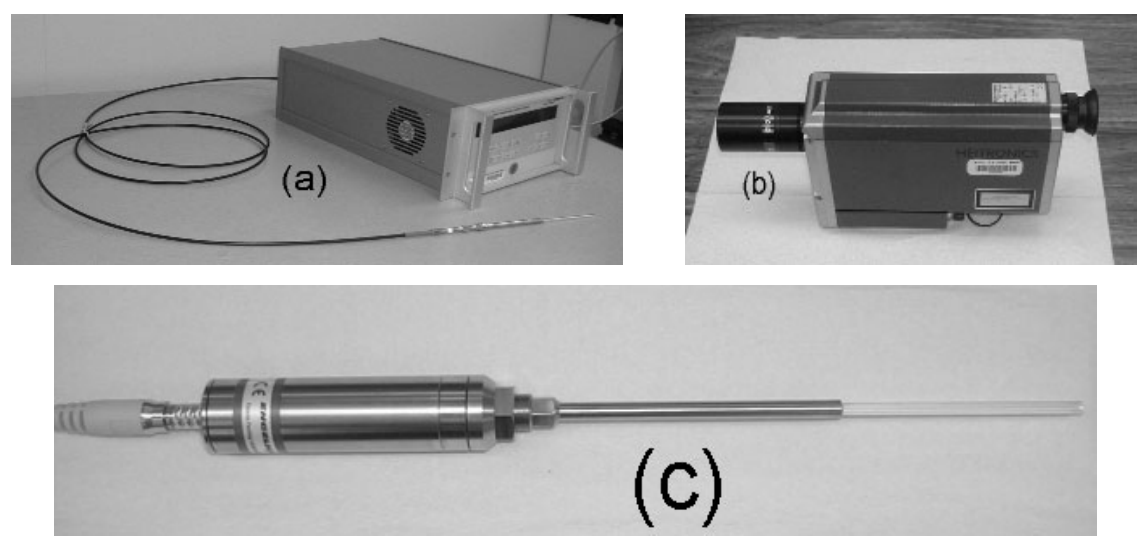

Fig. 1. (a) lightpipe radiation thermometer, (b) spot-type radiation thermometer, and (c) cableless lightpipe radiation thermometer.

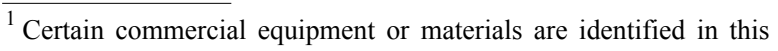
paper to foster understanding. Such identification does not imply recommendation or endorsement by the NIST, nor does it imply that the equipment or materials are necessarily the best available for the purpose.
} 
Na-HPBB shown in Fig. 2 is $25 \mathrm{~mm}$ in diameter and $48 \mathrm{~cm}$ in length, whereas its aperture opening is $22 \mathrm{~mm}$ in diameter. Surrounding the cylindrical cavity is a $90 \mathrm{~mm}$ diameter tube, which contains the sodium liquid and vapor. A condensing tube at the rear of the blackbody allows the metal vapor to liquefy back into the tube and at the same time serves as the conduit by which the tube is pressurized with helium. A Monte Carlo model [32] was used to estimate the cavity emissivity as $0.99992 \pm 0.00003$ for the wavelength range from $1 \mu \mathrm{m}$ to $5 \mu \mathrm{m}$ with an Inconel surface emissivity of 0.85 . The Na-HPBB temperature, which is measured by a gold-platinum $(\mathrm{Au} / \mathrm{Pt})$ thermocouple $(\mathrm{TC})$, is computer-controlled by regulating the pressure of the helium. Three type $\mathrm{S}$ thermocouples monitor the temperature in three zones along the cavity. Using the $\mathrm{Au} / \mathrm{Pt} \mathrm{TC}$ links the Na-HPBB temperature to the ITS-90. Further details of the Na-HPBB are given in [32].

Uncertainties $(k=1$ [67] is implied throughout this paper unless otherwise specified) for the Na-HPBB are provided in Table 1. The dominant component in the Na-HPBB temperature uncertainty is the blackbody radial uniformity as viewed and measured by a RT in front of the Na-HPBB. The blackbody stability and the uncertainty in the calibration of the Au-Pt TC are small in comparison with the dominant uncertainty.

Table 1. Uncertainties in ${ }^{\circ} \mathrm{C}$ for Na-HPBB

\begin{tabular}{ll}
\hline \hline \multicolumn{1}{c}{ Factor } & Uncertainty \\
\hline Na-HPBB radial uniformity & 0.29 \\
Na-HPBB length uniformity & 0.10 \\
Na-HPBB stability for 1 h & 0.03 \\
Au-Pt TC temperature & 0.005 \\
\hline Na-HPBB Temperature & 0.31 \\
\hline
\end{tabular}

\subsection{Calibration Procedures for Spot-Type Radiation Thermometers}

The procedures for preparing and operating the NaHPBB are the same, regardless of the RT type (LPRT, STRT, or CLRT). Safety checks are performed, prior to turning on the power for the Na-HPBB, to ensure adequate water cooling, sufficient helium, and the proper electrical connections. Next, the heater power is turned on, and the helium pressure adjusted to raise the blackbody temperature to a desired set-point temperature.

Before a STRT is calibrated, it is visually inspected for scratches or dents, breaks in cables, excessive dirt, or other obvious problems. If serious damage is discovered, it is immediately reported to the owner of the STRT. Otherwise, the lens, eyepiece, and the filters are cleaned with lens tissue paper and ethyl alcohol to remove fingerprints and sprayed with air to remove dust. Next, the front surface of the lens is positioned to a specified distance from the blackbody aperture, as shown in Fig. 3a. A level situated on top of the STRT is used to ensure that the STRT is horizontal. The yaw and pitch of the STRT are tweaked to be assured that the optical axis of the STRT is coincident with the geometrical center of the Na-HPBB. The centering process is usually done first roughly by using eyes to sight on the center and then more precisely by using a computer program to search for the radiometric center. Then, the STRT focus knob, if existent, is adjusted to find the maximum signal or temperature. After the Na-HPBB is stabilized to within $30 \mathrm{mK}$, three STRT measurements are acquired in one-minute intervals and are averaged. With each STRT reading, a measurement of the $\mathrm{Au} / \mathrm{Pt}$ TC is recorded. The three TC readings are also averaged, and the difference $\Delta T$, the TC temperature minus the average STRT temperature, is recorded as the offset temperature. To calculate the corrected temperature, the offset temperature is added to future RT readings.
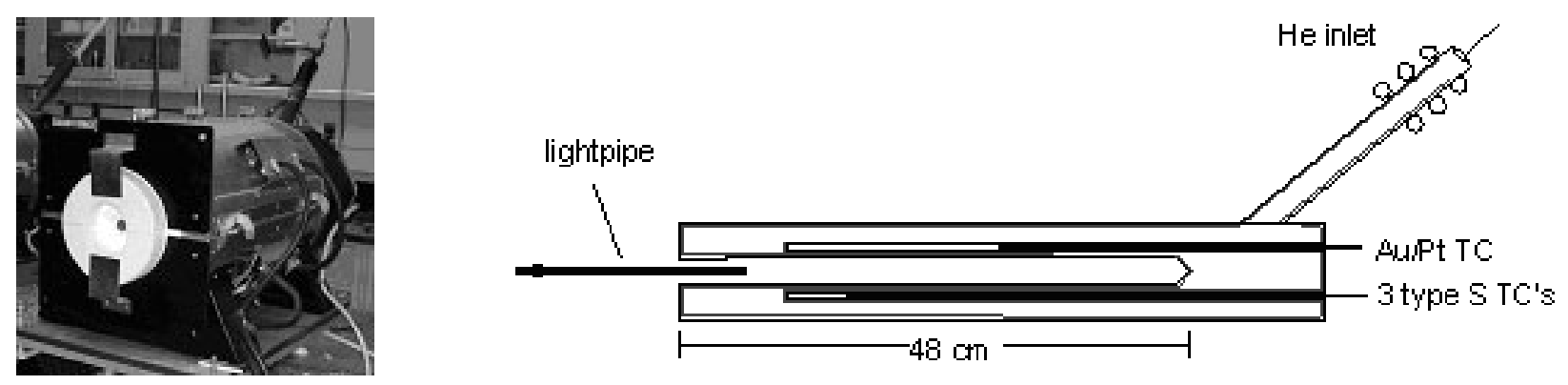

Fig. 2. Left: photograph of NIST sodium heat pipe blackbody. Right: schematic of sodium heat pipe blackbody with lightpipe properly inserted. 


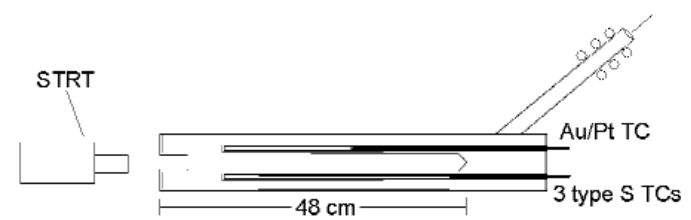

(a)

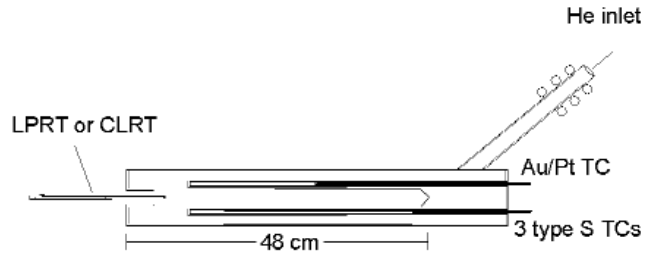

(b)

Fig. 3. (a) Calibration of STRT. (b) Calibration of LPRT or CLRT.

\subsection{Calibration Procedures for Lightpipe Radiation Thermometers and Cableless Lightpipe Radiation Thermometers}

On a routine basis, the LPRTs and CLRTs are calibrated against the Na-HPBB before and after measurements. The LPs undergoing calibration are visually inspected for dirt, and their tips cleaned with a tissue wiper or a cotton swab saturated with ethyl alcohol. After the Na-HPBB comes to a stable temperature and does not vary more than $30 \mathrm{mK}$, the LP is rapidly inserted into the Na-HPBB in Fig. 3b, measurements of the LPRT or CLRT indicated temperature are recorded, and the LP is removed before it heats up by more than $0.2{ }^{\circ} \mathrm{C}$. The measurements usually take about $5 \mathrm{~s}$ to $10 \mathrm{~s}$ and are referred to as a cold calibration. Before and after their use in our test bed experimental studies, a set of LPs is calibrated in this way, and the temperature of the $\mathrm{Au} / \mathrm{Pt} \mathrm{TC}$ is recorded. For each LP, three measurements are averaged and the difference, the average temperature minus the TC temperature, is recorded as the offset temperature. The temperature of the Na-HPBB is then increased to the next temperature, and the whole procedure repeated.

When the LPs are visually contaminated (with carbon deposits or other contaminants), or when the LP response in RTP measurements or calibration changes by more than $2{ }^{\circ} \mathrm{C}$, the LPs are cleaned using a flame cleaning procedure. With the outer sheath removed, the LP is first wiped with acetone and ethanol and then heated with an oxygen-methane flame to remove any contamination. Care is exercised to heat the LP slowly and uniformly to avoid damage.

After the LPs have been cleaned through the flaming process, or after the LPs are returned from the factory calibration, the sensor factor settings need to be adjusted. The adjustment is performed by changing the LP sensor factor setting until the LP indicated reading is within $0.02{ }^{\circ} \mathrm{C}$ of the $\mathrm{Au} / \mathrm{Pt} \mathrm{TC}$ reading for the NaHPBB at the highest calibration temperature, $900^{\circ} \mathrm{C}$. A few LP temperature readings are obtained for establishing repeatability. The LP sensor factor setting is recorded and stored for the remainder of the calibration procedure and for future LP measurements. It should be noted that after the LP is cleaned and calibrated, it remain attached to the LPRT until the next flame cleaning is required.

\subsection{Calibration and Measurement Uncertainties}

Table 2 displays the uncertainties for calibrating LPRTs. The principal uncertainty is the uncertainty in the Na-HPBB temperature determination from Table 1. In comparison with this uncertainty, the other uncertainties in the LPRT, stray radiation effects, and the NaHPBB emissivity, are negligible. Since it is very difficult to replicate the exact position and cable looping of the LPRTs in the calibration mode, the uncertainty due to the handling and positioning of the LPRTs is estimated to be about $2.0^{\circ} \mathrm{C}$. Although the uncertainty in the NIST calibration of LPRTs is only $0.31^{\circ} \mathrm{C}$, the total estimated uncertainty taking into account the handling uncertainty, is about $2.02{ }^{\circ} \mathrm{C}$.

Table 2. Typical uncertainties in ${ }^{\circ} \mathrm{C}$ for $\mathrm{Na}-\mathrm{HPBB}$ calibration of LPRTs

\begin{tabular}{lc}
\hline \hline \multicolumn{1}{c}{ Factor } & Uncertainty \\
\hline LPRT noise & 0.01 \\
LPRT short-term drift & 0.03 \\
Stray radiation & 0.00 \\
Blackbody emissivity & 0.03 \\
Na-HPBB temperature & 0.31 \\
\hline LPRT calibration & 0.31 \\
\hline LP cable handling & 2.00 \\
\hline LPRT total & 2.02 \\
\hline
\end{tabular}


Uncertainties for calibration of STRTs are shown in Table 3. The dominant uncertainty factors are the NaHPBB temperature uncertainty and the STRT resolution. The other uncertainties in the STRT, stray radiation effects, and the Na-HPBB emissivity, are small. The total estimated uncertainty in a typical calibration of a STRT using the Na-HPBB is about $1.05^{\circ} \mathrm{C}$ and is limited by the resolution of the STRT. Improving the STRT resolution will decrease the total uncertainty.

Table 3. Typical uncertainties in ${ }^{\circ} \mathrm{C}$ for Na-HPBB calibration of STRTs

\begin{tabular}{lc}
\hline \hline \multicolumn{1}{c}{ Factor } & Uncertainty \\
\hline STRT resolution & 1.00 \\
STRT short-term drift & 0.03 \\
Stray radiation & 0.00 \\
Blackbody emissivity & 0.03 \\
Na-HPBB temperature & 0.31 \\
\hline STRT calibration total & 1.05 \\
\hline
\end{tabular}

Table 4 shows the uncertainties for calibrating a CLRT using the Na-HPBB. The uncertainties for the CLRT calibration are exactly the same as the ones for the LPRT calibration with one exception. That is, the large uncertainty component due to the handling of the cables is eliminated. The total estimated uncertainty in a typical calibration of a CLRT using the Na-HPBB is about $0.31{ }^{\circ} \mathrm{C}$.

Table 4. Typical uncertainties in ${ }^{\circ} \mathrm{C}$ for heat pipe blackbody calibration of cableless lightpipe radiation thermometers

\begin{tabular}{lc}
\hline \hline \multicolumn{1}{c}{ Factor } & Uncertainty \\
\hline CLRT noise & 0.01 \\
CLRT short-term drift & 0.03 \\
Stray radiation & 0.00 \\
Blackbody emissivity & 0.03 \\
Na-HPBB temperature & 0.31 \\
\hline CLRT calibration total & 0.31 \\
\hline
\end{tabular}

In Tables 2, 3, and 4, the uncertainties of $0.31{ }^{\circ} \mathrm{C}$, $1.05^{\circ} \mathrm{C}$, and $0.31{ }^{\circ} \mathrm{C}$, respectively, represent the uncertainty of the RT calibration. Other factors, which will increase the uncertainty, need to be considered when approximating the total uncertainty in using the RT for temperature measurement.

\subsection{LPRT Stability}

After use in the RTP test bed for about a month, the LPRTs are calibrated again to check for variability during use. In Fig. 4, typical calibrations of four LPs are shown for a period of 1 year, including those before and after cleaning of the LPRT. Variations during this period of time were less than $1{ }^{\circ} \mathrm{C}$ for all four LPs.

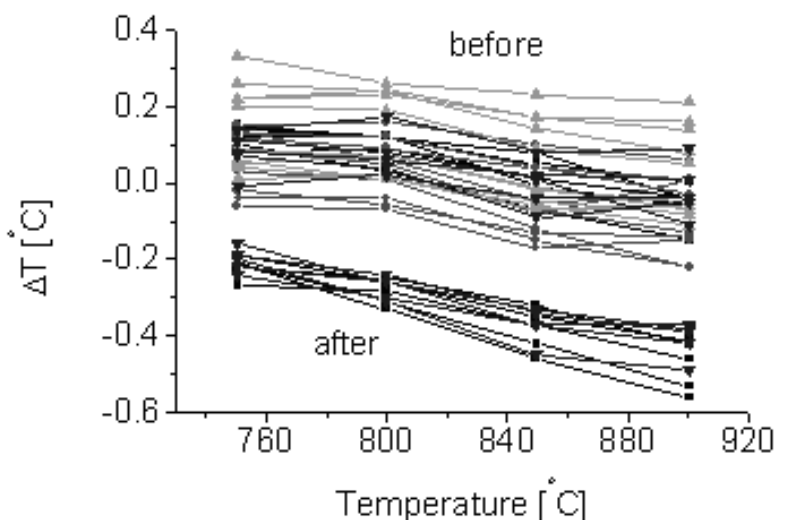

Fig. 4. LPRT calibration in cold mode, including those before and after cleaning of the LPRT.

\subsection{LPRT Application Issues: Factory vs NIST Calibrations and Hot vs Cold Measurements}

Applying calibrated LPRTs in an industrial or process application is more complicated and requires more analysis for determination of temperature, as well as establishing uncertainty limits and traceability. In this section, we present two issues associated with using LPRTs in applications outside of a well-controlled laboratory environment. Differentiation is made between hot and cold calibration for LPRTs. Our recommendation is to calibrate in the same fashion as the application.

Three LPs from different vendors, using the factoryset sensor factors, were calibrated using the Na-HPBB as soon as they were received at NIST. The differences between the LPRT indicated temperatures in the factory hot-mode calibrations and the actual temperatures measured with the $\mathrm{Au} / \mathrm{Pt} \mathrm{TCs}$ in the Na-HPBB are shown in Fig. 5a. From the results for three LPRT systems (LPRT1, LPRT2, LPRT3), each system consisting of four LPs, the variations among the four LPs in LPRT2 can be as high as $7.6^{\circ} \mathrm{C}$, while those for LPRT1 are as low as $1.6^{\circ} \mathrm{C}$. Thus, without measuring this difference shown in Fig. 5a, the user will not know the magnitude of the uncertainty in using a set of LPs. 

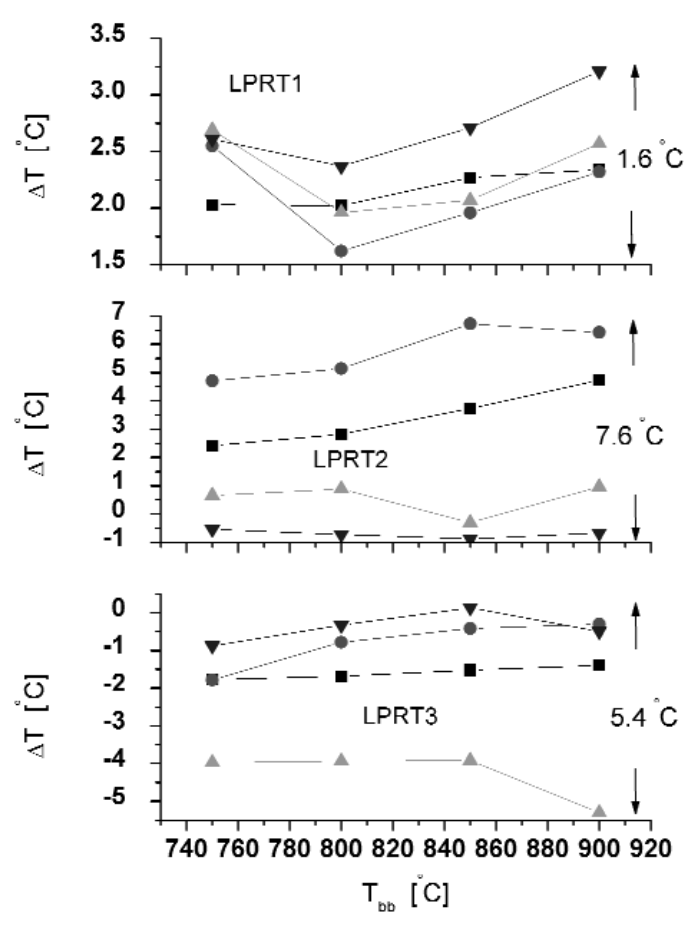

(a)
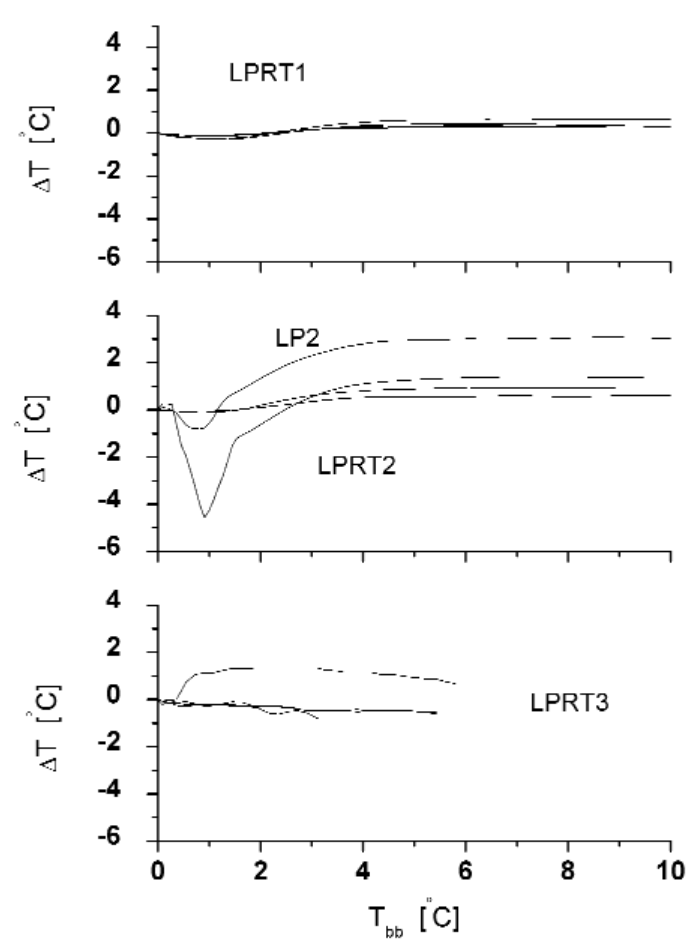

(b)

Fig. 5. (a) Factory vs NIST hot calibrations. (b) Hot vs cold calibrations. (Values for four different LPs are shown in each graph.)

In the Na-HPBB, time histories of all of the LPs at $850{ }^{\circ} \mathrm{C}$ are shown in Fig. 5 b. After the LP is inserted into the Na-HPBB for a few seconds, the LPRT indicated temperature initially remained fairly constant, dipped, and then rose above the initial temperature to a steady temperature. Cold calibrations were performed in the initial period when the temperature was still constant, while hot calibrations were performed after the $\mathrm{Na}-\mathrm{HPBB}$ was stable during the second temperature rise. Although most LPRTs behaved in this manner, other patterns have been observed. However, in general, there was a constant plateau during the first $30 \mathrm{~s}$ or 1 min (cold) and again after 5 min (hot) from insertion. Significant differences exist between hot and cold LP calibrations in Fig. $5 \mathrm{~b}$ of up to $2.5 \mathrm{~K}$ for LPRT2, while only modest differences of up to $0.7 \mathrm{~K}$ for LPRT1 were exhibited. These findings correlated very well with visual and transmission measurements to be discussed in Sec. 4.4.

When performing hot calibrations, the following issues can influence the accuracy of calibration and measurement errors in RTP tools. First, the LP can become contaminated by ceramic particles or impurities in the blackbody, especially if the LP is left in the blackbody for more than several minutes. Second, the inserted LP disturbs the temperature distribution and thus changes the relationship between the spectral radiance sensed by the LPRT and the reference temperature of the blackbody. Quantifying this perturbation requires further experiments or heat-transfer modeling. Third, the uncertainty of the measured blackbody temperature needs to be determined. If TCs are used for the reference temperature, an uncertainty analysis needs to be performed so that the blackbody temperature uncertainty can be related to the TC uncertainty, as well as, to other features of the blackbody, such as temperature non-uniformities and non-unity emissivity. If other blackbody sources, such as fixed points, are used, the uniformity and accuracy of these blackbodies need to be characterized. Fourth, the frequency of recalibration of the NIST-traceable TC providing the reference blackbody temperature needs to be established to avoid significant changes with use. Fifth, leakage can occur through the lateral side of the LP as a consequence of surface roughness, which can be worsened by the presence of gradients in the refractive index along the LP. Leakage can be minimized by using cold calibrations, or by using a cold radiation shield such as the cold sleeve. The first two issues above are unique to hot calibrations, while the last issue can be minimized using 
cold calibrations. The other two issues are common to both hot and cold calibrations.

To make accurate LP temperature measurements, it is necessary to understand the accuracy of factory calibrations, the difference between hot and cold calibrations, and the importance of visualization and measurement techniques in defect detection for LPs. An understanding of these practical principles will be helpful not only in making more accurate LP temperature measurements but also in choosing a quality LP and in developing an improved LP calibration system.

\subsection{Calibration Services}

Calibration services are available at NIST for RTs from $15{ }^{\circ} \mathrm{C}$ to $2700^{\circ} \mathrm{C}$ using various blackbodies. For the temperature range from $700{ }^{\circ} \mathrm{C}$ to $900{ }^{\circ} \mathrm{C}$, the NaHPBB is used as the standard blackbody source. Calibration reports are issued giving the thermodynamic temperature of the reference blackbody (BB) vs the radiation thermometer (RT) display reading, output current, or output voltage. Users can order one of two calibration tests from the NIST Calibration Services manual [68] or from the NIST Calibration Services website [69]. The first is service ID number 35084C for a Radiance Temperature Standard, Radiation Thermometer $\left(700{ }^{\circ} \mathrm{C}\right.$ to $900{ }^{\circ} \mathrm{C}$, three points). This calibration is a set-fee measurement at any three temperatures between $700{ }^{\circ} \mathrm{C}$ and $900{ }^{\circ} \mathrm{C}$. The second is service ID number $35080 \mathrm{~S}$ for Special Tests of Radiation Thermometers $\left(15{ }^{\circ} \mathrm{C}\right.$ to $\left.900{ }^{\circ} \mathrm{C}\right)$. Since this special allows the user to customize the measurement set, the price is uniquely determined for each situation. Any questions or requests for quotes may be addressed to the author at benjamin.tsai@nist.gov.

\section{Characterization}

Throughout this section, data from LPRTs for three different vendors are discussed. The term LPRT refers to the measurement system including the controller unit, the quartz fiber-optic cable, and the sapphire LP. Hereafter, the three LPRTs will be referred to as simply LPRT1, LPRT2, and LPRT3. Each LPRT consists of four channels, which are connected to four sapphire LPs (LP1, LP2, LP3, and LP4). Since there are twelve LPs in total, each LP will be identified by LPRT and LP numbers (e.g., LPRT2-LP3). The term LP only refers to the sapphire rod, which is the part of the LPRT aimed directly at the target. The LPs are of varying lengths, but they are $2 \mathrm{~mm}$ in diameter and are typically surrounded by a $4 \mathrm{~mm}$ outer diameter sapphire sheath. In normal operation for measuring the spectral radiance temperature, the LPs are connected to a $1 \mathrm{~mm}$ diameter quartz fiber-optic cable. The exposed length of sapphire sheath is about $9 \mathrm{~cm}$. For more details, see [32].

\subsection{Point Spread Response}

The effective target area on a silicon wafer viewed by the LPRT was determined in the point spread response (PSR) facility. Attached to a precision $x-y$ stage, the LP was translated under computer control in a vertical plane to measure the radiation emanating from a small stationary lamp bulb (about $2 \mathrm{~mm}$ ). The normal distance from the source to the vertical LP plane was carefully set to coincide with the corresponding wafer-to-LP tip gap separation distances in the NIST test bed. From the resulting intensity distribution of the measured radiation, the wafer spot was chosen to be the area that enclosed intensities greater than $1 \%$ of the maximum intensity. This technique was repeated for different lamp-to-LP tip gap separations. The contours of the PSR measurement in Fig. 6 indicate the fraction (with 1.00 being equal to $100 \%$ ) of the maximum intensity measured at the origin of the vertical plane in which the LP is translated. This origin is located at the

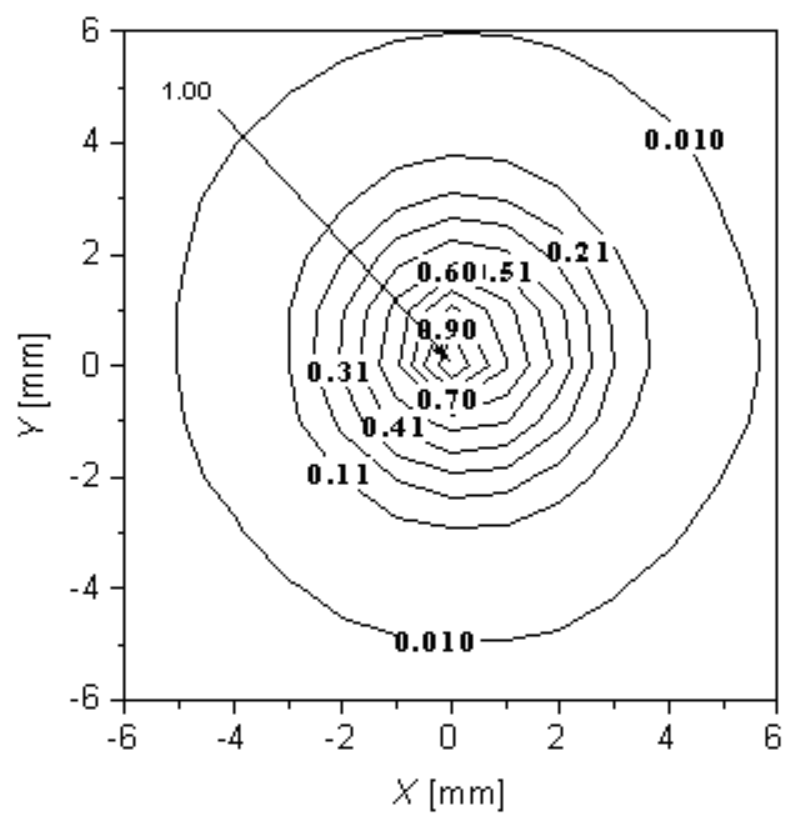

Fig. 6. Target size determination from a small lamp bulb $12 \mathrm{~mm}$ from front of LPRT1-LP1. 
same $X$ and $Y$ location as the lamp bulb. Figure 6 shows that the target size for a gap separation of $12 \mathrm{~mm}$ is about $12 \mathrm{~mm}$ in diameter for LPRT1-LP1. This spotsize information is useful in the modeling of the effective emissivity, determination of the corrected LPRT spectral radiance temperature, and setting up the LPRT for measurements.

\subsection{Absolute Spectral Response}

A spectral characterization of the LPRTs was performed using the Spectral Comparator Facility (SCF) [70], in which the LP fixed on a linear translation stage was aligned with the center of a monochromator slit and was used to collect the output of a spectrally filtered beam from a quartz-halogen source through the monochromator. This measurement was compared with that using a standard trap detector, calibrated previously against the NIST Primary Optical Watt Radiometer (POWR) [71], the successor of the NIST High Accuracy Cryogenic Radiometer (HACR) [71].

The relative response curves, or the absolute spectral response curves normalized to unity, for three LPs (LPRT1-LP1，LPRT3-LP3，LPRT3-LP4) obtained using the SCF are depicted in Fig. 7 and are very similar. Based on the full width at half maximum, the peak for all three LPs is centered about an effective wavelength of about $955 \mathrm{~nm}$ with a bandwidth of $40 \mathrm{~nm}$. The effective wavelength is critical in the determination of the surface temperature from the LPRT spectral radiance temperature by using the temperature measurement equation. In addition, the effective wavelength and the spectral bandwidth are useful in the estimation

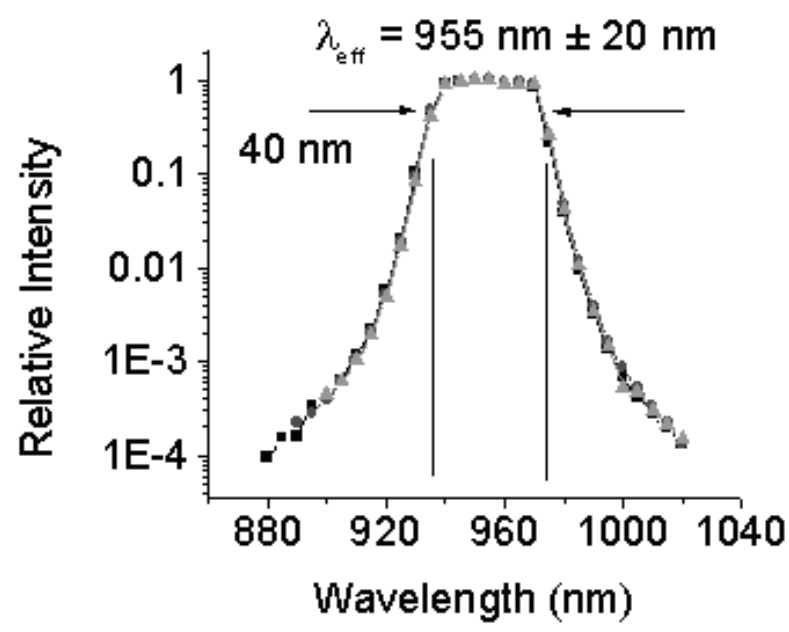

Fig. 7. Relative spectral response for LPRT1-LP1, LPRT3-LP3, and LPRT3-LP3, using the SCF. of the temperature uncertainty [39]. Outside of the $40 \mathrm{~nm}$ bandwidth, the relative response quickly decreases four orders of magnitude outside of a bandwidth of about $140 \mathrm{~nm}$. This information can also aid in the uncertainty analysis as well as in the quality control of LPs. The similarity of all three curves in Fig. 7 reveals the consistency and quality of these LPs and their filters, which come from two different vendors.

\subsection{Temporal Response}

In Figure 8, the temporal stability for a period of $10 \mathrm{~min}$ is shown for two LPs, LPRT1 and LPRT2. The results were obtained by irradiation from a helium-neon $(\mathrm{HeNe})$ laser into the LP while it was in an integrating sphere. The resulting variations at room temperature for LPRT1 and LPRT2 were about $\pm 0.06 \%$ and $\pm 0.04 \%$, respectively. This corresponds to a temperature standard uncertainty at $1000{ }^{\circ} \mathrm{C}$ of $0.064{ }^{\circ} \mathrm{C}$ and $0.043{ }^{\circ} \mathrm{C}$, respectively.

\subsection{Optical Characterization of Lightpipes}

A measure of the LP quality is the radiation scattering from the lateral surface along the length of the LP. For an ideal LP, the scattering effect will be zero. However, in reality, defects in the manufacturing process can lead to surface imperfections that can cause loss of radiation from the lateral surface. To determine whether such defects are contributing to differences in calibration, two specific studies were conducted for LPRT1-LP2 and LPRT2-LP2. Both studies were made by passing a HeNe laser beam along the LP and by observing the circumference for irregular patterns. The first study qualitatively showed a relatively large number of bright spots for LPRT2-LP2. This visual study emphasized the need for a more quantitative experiment to determine the radiation loss from the lateral surface due to scattering. An experiment using an integrating sphere and a silicon detector to measure the transmitted and scattered signals constituted the second study that was conducted on the same two LPs used in the first study.

\subsubsection{Visual Inspection of Lateral Surfaces}

A HeNe laser beam $(0.95 \mathrm{~mW}$ at $637 \mathrm{~nm})$ was used for irradiating the end of the LP in both studies. A $1 \mathrm{~mm}$ diameter quartz fiber-optic cable transmitted the beam from the laser to the $2 \mathrm{~mm}$ diameter sapphire LP. To compare the whole length of sapphire rod from both LPs, the LPs in Fig. 9 were photographed while the 


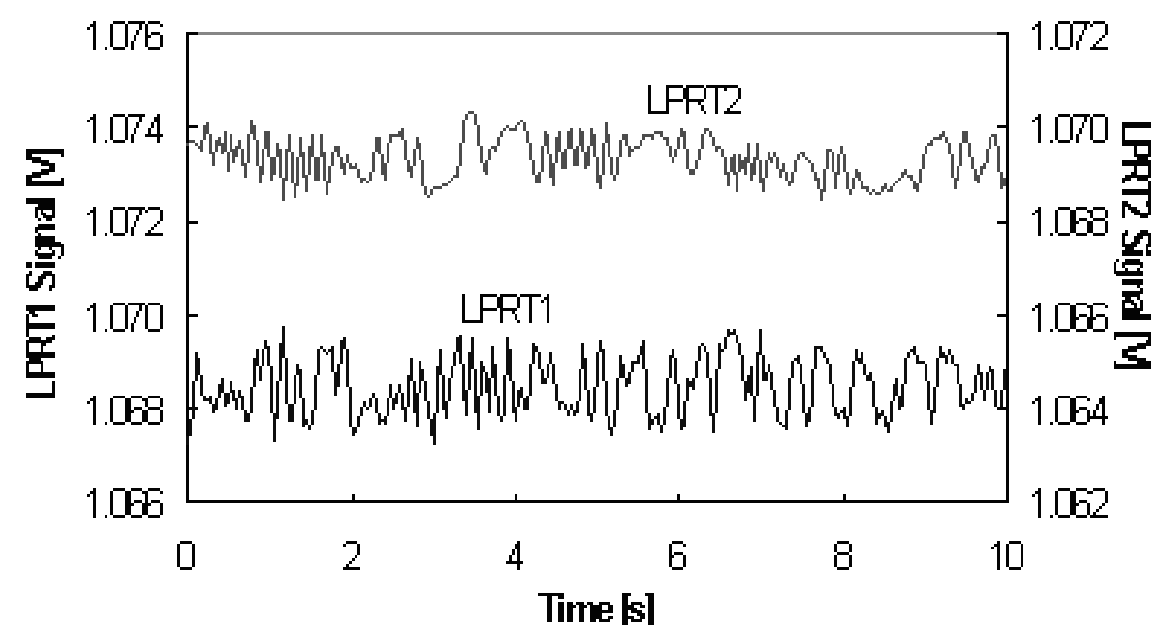

Fig. 8. Typical temporal stability for two LPs under stable temperature conditions.

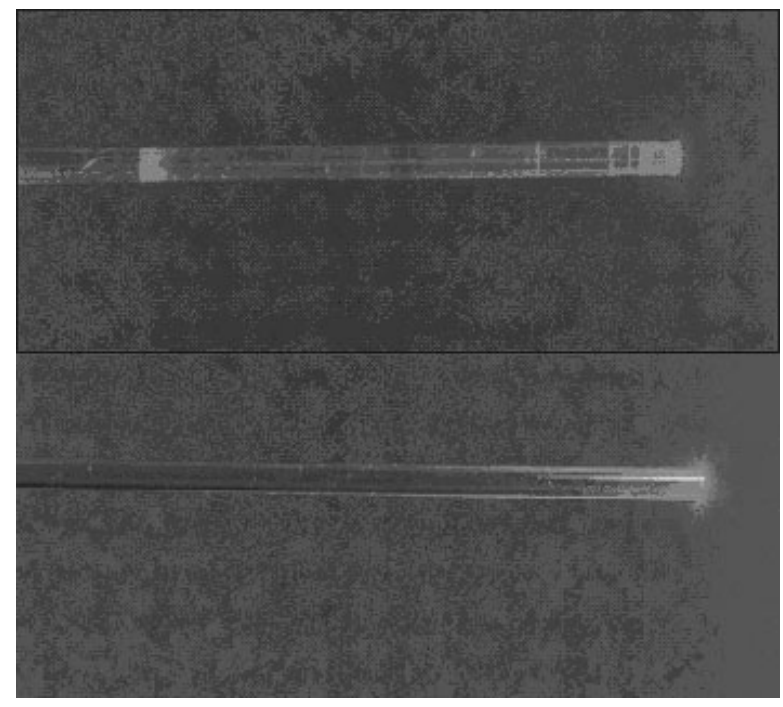

Fig. 9. Comparison of a lightpipe with excessive scattering (top, LPRT2-LP2) with a good lightpipe (bottom, LPRT1-LP2) using HeNe laser.

HeNe laser illuminated the LP. The top part of the figure (LPRT2-LP2) reveals many defect locations where significant scattering can take place, while the bottom (LPRT1-LP2) reveals a more perfect sapphire crystal structure, resulting in less scattering. Figure 9 clearly shows the utility of a simple visualization technique, such as the one used in this study, to detect scattering defects in LPs before calibration.

\subsubsection{Quantifying Lateral Scattering}

For the second study, an integrating sphere, about $18 \mathrm{~cm}$ in diameter, fitted with a silicon detector was used to measure the radiance of the laser beam with and without the LP inserted. The laser beam entering the sphere was distributed uniformly on the inner surface of the sphere by multiple reflections. The output of the silicon detector was proportional to the laser power incident on the sphere surface. The low-level current signal from the silicon detector was amplified by a current amplifier, and the output voltage measured by a digital voltmeter. Data recording by the voltmeter was performed by a computer.

The two positions of the LP in the integrating sphere, A and B, in the second study are shown in Fig. 10. In Position A, the tip of the LP was positioned in the plane of the integrating sphere aperture. In this position, only the portion of the radiation transmitted through the
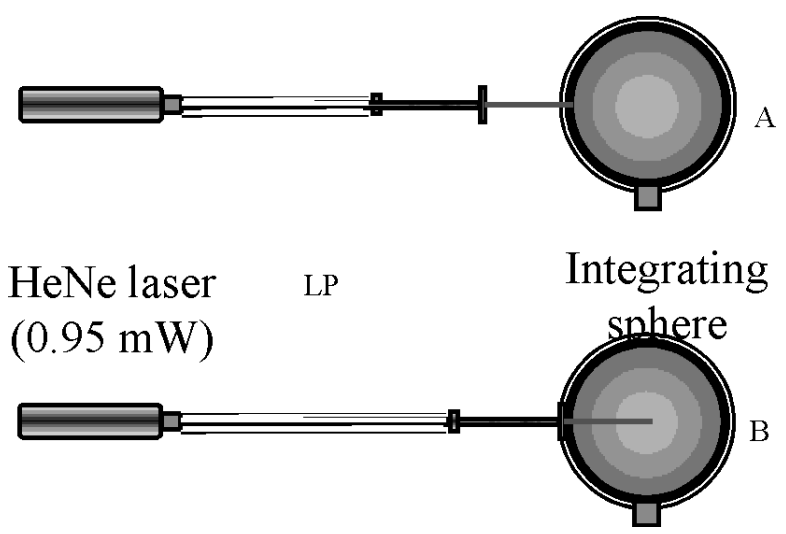

Fig. 10. LP positions for measuring transmitted and scattered signals. 
length of the LP was distributed onto the integrating sphere surface. In Position B, the LP was inserted inside the sphere cavity with the exposed portion of the sapphire sheath also inside the cavity. The radiation loss from the sheath was also captured, along with the transmitted beam, by the integrating sphere surface. The difference between the readings in Position A and Position B was a measure of the radiation loss through the lateral surface of the LP. Since this radiation loss was less than $1 \%$ of total power and since intermittent surges in power, lasting several seconds, occurred periodically, the laser measurements were made over a long period of time, and an interval, during which the laser power was stable, was chosen for the analysis. Table 5 shows the final results of the measurements for LPRT1LP2 and LPRT2-LP2 before and after cleaning with a flame. For all measurements, the dark signal, which was the measured signal taken without the laser and with the integrating sphere aperture covered, was less than $0.001 \mathrm{mV}$.

Table 5. Summary of LP measurements in the integrating sphere

\begin{tabular}{lcccc}
\hline \hline \multirow{2}{*}{$\begin{array}{c}\text { Before or after } \\
\text { cleaning }\end{array}$} & LP & \multicolumn{2}{c}{ Location } & Difference \\
\hline make & Aperture & Inside & {$[\%]$} \\
Before & LPRT1-LP2 & $1.04356 \mathrm{~V}$ & $1.04803 \mathrm{~V}$ & 0.43 \\
Before & LPRT2-LP2 & $1.08129 \mathrm{~V}$ & $1.09079 \mathrm{~V}$ & 0.88 \\
After & LPRT1-LP2 & $1.06788 \mathrm{~V}$ & $1.06901 \mathrm{~V}$ & 0.11 \\
After & LPRT2-LP2 & $1.06654 \mathrm{~V}$ & $1.06947 \mathrm{~V}$ & 0.27 \\
\hline
\end{tabular}

LPRT2-LP2 showed nearly twice as much radiation loss through the lateral side as LPRT1-LP2. This correlated with LPRT2-LP2 having more defects. Hence, the present study suggests that the integrating sphere method can be used to identify and qualify LPs suitable for use in RTP chambers to achieve the desired accuracy. Such qualified LPs can then be calibrated for spectral radiance temperature using primary-standard blackbodies. The method can be improved by using a more stable laser.

\subsubsection{Correlation of Optical Characterization Results With Hot/Cold Calibration Results}

In Sec. 3.7, LPRT2 exhibited differences between hot and cold LP calibrations of up to $2.5 \mathrm{~K}$, while LPRT1 only showed differences of up to $0.7 \mathrm{~K}$. The optical characterization study shows that visual effects could be correlated with quantitative measurements. Visual defects as well as the ratios of the scattered signal to the transmitted signal have direct relationships with the amount of thermal leakage as measured by the net temperature rise in $10 \mathrm{~min}$. The visual defects and transmission measurements both have a strong correlation with the difference between hot and cold LP calibrations. LPRT2-LP2 exhibited a large difference of $2.5 \mathrm{~K}$ in Fig. 5b and a large slope in Fig. 5a. It also showed the most visual defects from the optical characterization. On the other hand, LPRT1-LP2 showed only a difference of $0.5 \mathrm{~K}$ in Fig. $5 \mathrm{~b}$ and a slight slope in Fig. 5a. This LP was relatively clear of visual defects from the optical characterization. In order to make accurate LP temperature measurements, it is necessary to understand the accuracy of factory calibrations, the difference between hot and cold calibrations, and the importance of visualization and measurement techniques in defect detection for LPs. Both types of experiments are crucial in detecting LPs that may exhibit significant scattering.

\subsection{Stray Light Effects on the LPRT Indicated Temperature}

Two experiments were performed with the NaHPBB to study the stray light effects on the LPRT indicated temperature. The first examined the influence of a hot environment on the indicated LPRT temperature by surrounding the LP lateral surface in the furnace of Fig. 11 and heating it while the LP was aimed at a constant radiance source, the Na-HPBB. The increases in the LP indicated temperature and the resulting radiance were plotted as a function of the furnace temperature for four different initial LP indicated temperatures $T_{\mathrm{o}}$ : $300^{\circ} \mathrm{C}, 680^{\circ} \mathrm{C}, 730^{\circ} \mathrm{C}$, and $780^{\circ} \mathrm{C}$. Figure $12 \mathrm{a}$ shows that for LPRT2-LP3 the temperature increase was largest at the highest furnace temperature $\left(950^{\circ} \mathrm{C}\right)$, but it was always less than $4{ }^{\circ} \mathrm{C}$ when the furnace temperature was at or below the Na-HPBB temperature. However, when the temperature differences are converted to radiance differences, the radiance increases in Fig. $12 \mathrm{~b}$ are independent of the Na-HPBB temperature. Thus, extraneous radiation can reach the LP through its lateral surface, but the radiance increase is only dependent on the temperature of the LP surroundings.

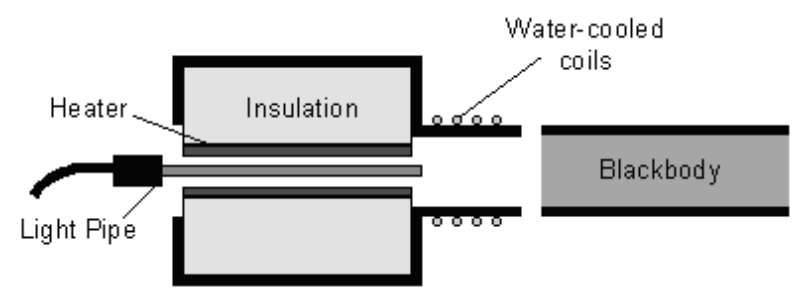

Fig. 11. Schematic of furnace experiment. 

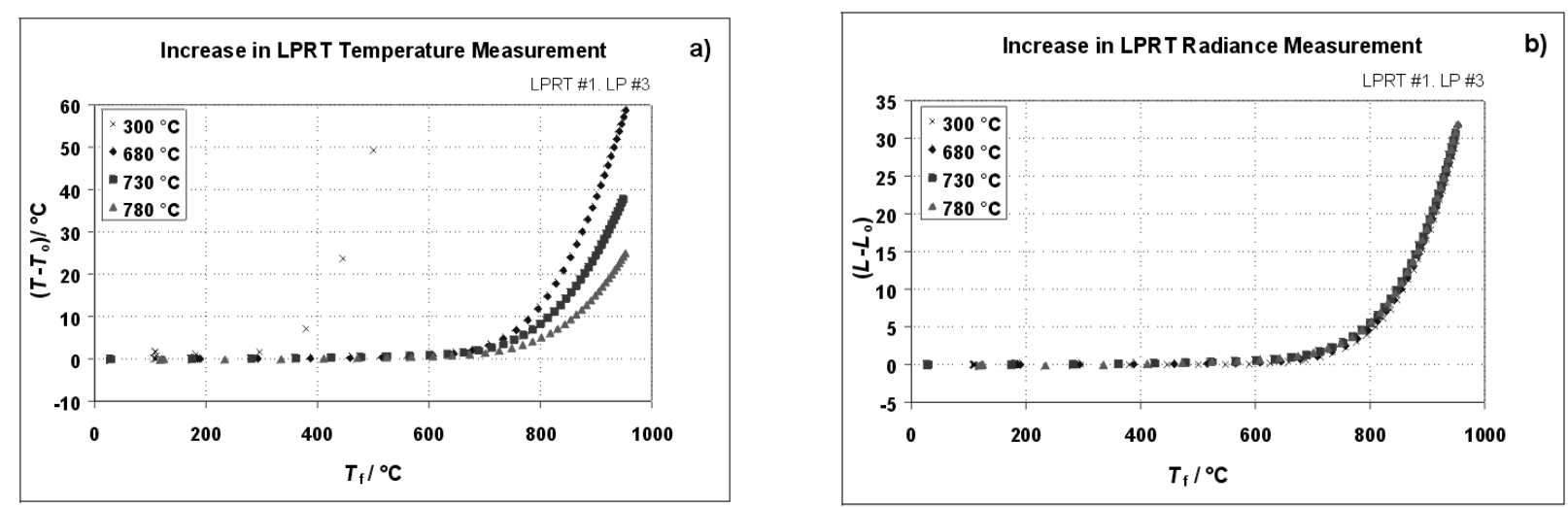

Fig. 12. Graphs as function of furnace temperature for a) temperature increases and b) radiance increases.

The second experiment, illustrated in Fig. 13, examined the influence of the Na-HPBB environment on the temperature indicated by an LPRT by taking measurements with and without a water-cooled, stainless-steel sleeve, which maintained the LP temperature below $100{ }^{\circ} \mathrm{C}$ and blocked radiation from entering its sides. The temperature history for LPRT2-LP3 in Fig. 14 shows that the indicated temperature without the cold sleeve drifted higher by $2{ }^{\circ} \mathrm{C}$ over $400 \mathrm{~s}$ before becoming steady, and the initial indicated temperature was higher by $2{ }^{\circ} \mathrm{C}$ before the LP was significantly heated. With the cold sleeve, the LPRT temperature did not drift. The results at $t=0$ quantify the blackbody calibration error due to light scatter from irradiation of the unsleeved LP from the sides. The drift in indicated temperature of the unsleeved LP over the first $400 \mathrm{~s}$ in the Na-HPBB suggested that additional radiation was emitted from the LP after it reached a sufficiently high temperature. Perhaps this emission was due to impurities in the LP sapphire crystal. This result shows that some LPs are less susceptible to extraneous radiation than others and suggests that better manufacturing techniques or materials for LPs can minimize calibration errors due to these effects $[33,79]$.

\subsection{Discussions and Recommendations}

Based upon our LPRT calibration and characterization experiences at NIST, we offer the following recommendations for users of LPRTs in calibration or measurement applications:

1. Visually inspect the LP first. Before any measurement is performed, the LP should be inspected for defects. A visual inspection can detect macroscopic chips and nicks. For more detail, the simple laser techniques and the more complex methods using integrat-

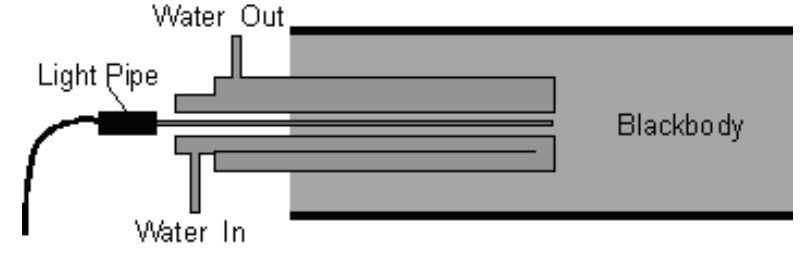

Fig. 13. Schematic of cold sleeve experiment.

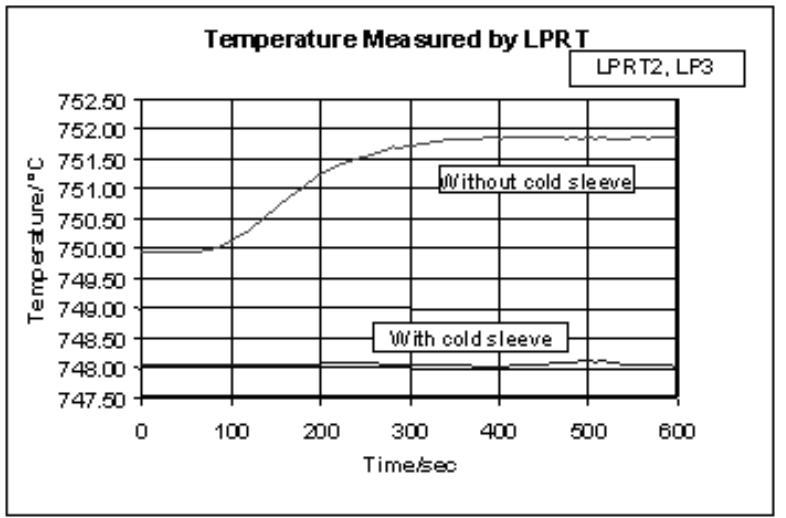

Fig. 14. Temperature indicated by LPRT1-LP3 in the $750^{\circ} \mathrm{C}$ Na$\mathrm{HPBB}$ as a function of time.

ing spheres or hot furnaces can assist in qualifying high-quality LPs.

2. Understand the factory calibration. When factory calibration data is available, the user should always try to verify the data when possible. The user should find out whether the factory calibrations were performed using the hot or cold calibration mode. The LP calibrations should then be checked using blackbody or other radiance sources for determining the spectral radiance temperature. Alternatively, the user could implement an in situ LPRT calibration method, such as the NIST thinfilm TC test wafer [21], to determine the surface tem- 
perature. If the results match the factory data, then the user can proceed with the LP measurements. Otherwise, the user should determine which set of calibrations to use by selecting the calibration conditions that best fit the measurement conditions. If the user is confident of the checking process and conditions, then the user calibration should be employed in LP measurements. It is good practice to check the factory calibrations against available blackbodies or other sources of low radiance temperature uncertainty.

3. Characterize the LPRT. The LPRTs should be characterized spectrally, spatially, and temporally with available resources. The LPs should be measured in the appropriate wavelength region to check the peak effective wavelength and the narrowness of the bandwidth for single-wavelength temperature measurements. Some check of the point spread response should be performed to estimate the field of view of the LPs to assist in analysis and modeling. The drift of the LPs for an appropriate period of time should be determined for the LPs at several temperatures to help assess the measurement uncertainties.

4. Minimize lateral scattering. Wherever possible, a method to minimize lateral scattering through the LP, such as a cold sleeve, should be used for cold calibrations. This will ensure that extraneous radiation is eliminated in LP calibrations and that the LP remains at a cold temperature.

5. Calibrate the LPRT as it will be used. The cardinal rule of LPRT calibrations is to calibrate in the same manner or as close to the same way in which it will be used. If the LP tip will be used in a cooled environment, such as the NIST RTP test bed, then the LP tip should be calibrated in the cold mode. If the LP tip will operate in a hot surroundings, then the LP tip should calibrated in the hot mode. It should be noted that the LP tip may be the only hot part in the cold mode. An understanding of the LPRT surroundings will aid in making better LP calibrations.

6. Calibrate the LPRT using blackbodies with traceable calibrations. The LPRT should be calibrated using blackbodies traceable to the SI unit of temperature. For highest accuracy, the spectral radiance of the blackbodies should be traceable to blackbodies at NIST or another national measurement institute (NMI). Alternatively, the temperature of the blackbodies could be traceable to the blackbody TC, which is traceable to the SI unit through an NMI.

7. Calibrate before and after use. Immediately before and after LP use, the LPs should be calibrated to check for any systematic drift or change. If there is any significant change in calibration, the LPs should be inspect- ed again for any damage or contamination during measurement, moving, or shipping of the LPs.

These practical principles have been formed from our experience with calibrations and measurements of LPs from several vendors. Following these guidelines wherever possible can ensure highly accurate LP calibrations and temperature measurements on the ITS-90.

\section{Comparison With Thin-Film Thermocouple Wafers}

\subsection{Experimental Procedure and Equipment}

The silicon calibration wafer in Fig. 15 was instrumented with the new wire Pt/Pd TCs $[73,74]$ and the new $\mathrm{Rh} / \mathrm{Pt}$ TFTCs [19]. The region at the center of the wafer in close proximity to the TC junctions is the primary target for sighting by the LPRT. The thin films were sputter deposited on oxidized silicon wafers using physical masks for the $0.5 \mathrm{~mm}$ thick metal films of $99.99 \% \mathrm{Pt}$ and $99.95 \% \mathrm{Rh}$, and the films were bonded to the $\mathrm{SiO}_{2}$ with sputter-deposited Ti. This procedure is described in more detail by Kreider and DiMeo [18]. The thin-film pattern included welding pads $10 \mathrm{~mm}$ from the edge of the wafer for the $0.25 \mathrm{~mm}$ diameter $\mathrm{Pt} / \mathrm{Pd} \mathrm{TC}$ wires. The uncertainty in temperature measurement of the thin-film thermocouple junction with this design is $0.3{ }^{\circ} \mathrm{C}$ with a temperature difference of up to $10^{\circ} \mathrm{C}$ from the center to the edge of the wafer.

The LPRTs were first calibrated using the Na-HPBB according to the procedures described in Sec. 3. Then the LPRTs were carefully transported without disconnecting cables and installed in the RTP test bed in Fig. 16. A detailed description of the test bed can be found in Ref. [36]. Comparisons between the temperatures measured by the TCs and the LPRTs in the RTP test bed were performed after reaching steady state while a constant heating power was applied.

\subsection{In-Situ Calibration of LPRTs}

Figure 17 shows a comparison between the temperatures measured by the thin-film thermocouple wafer $\left(T_{\text {tc }}\right)$ and those measured by the LPRT $\left(T_{\lambda}\right)$ for a diffuse and a specular shield with a wafer/shield spacing of $12.5 \mathrm{~mm}$. The values of $T_{\mathrm{tc}}-T_{\lambda}$ for the specular shield shown in squares are $1.8^{\circ} \mathrm{C} \pm 0.7^{\circ} \mathrm{C}$, while the values for the diffuse shield are larger. This is expected, because the reflectance of the specular gold shield ( $\rho=$ 0.993 ) is higher than that of the diffuse gold shield ( $\rho=$ 

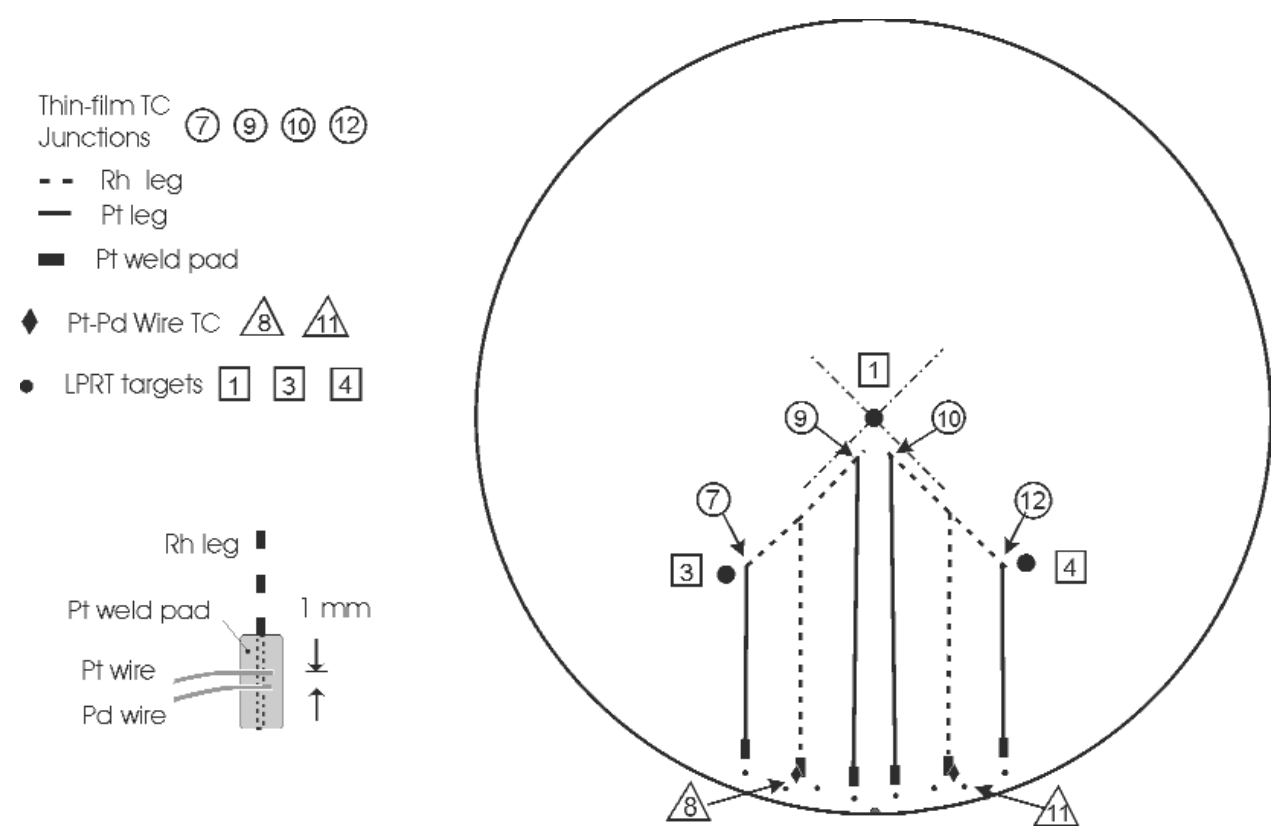

Fig. 15. Schematic of the wafer layout with thin-film thermocouples, wire thermocouples, and lightpipe radiation thermometer targets.

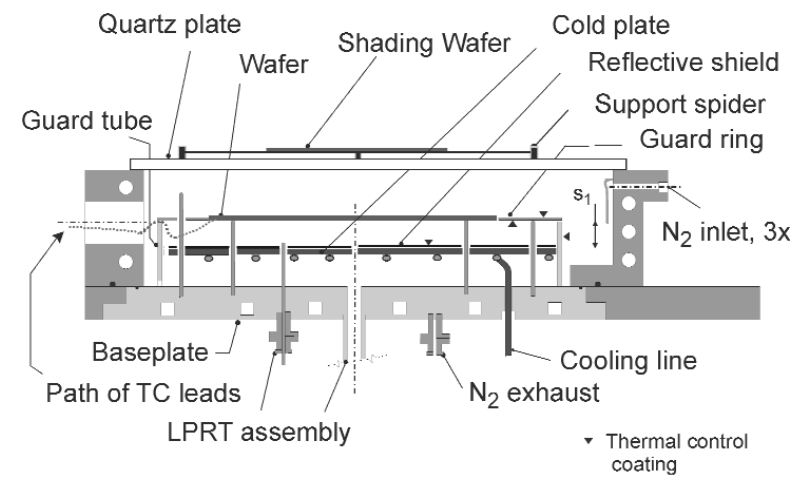

Fig. 16. The NIST RTP test bed.

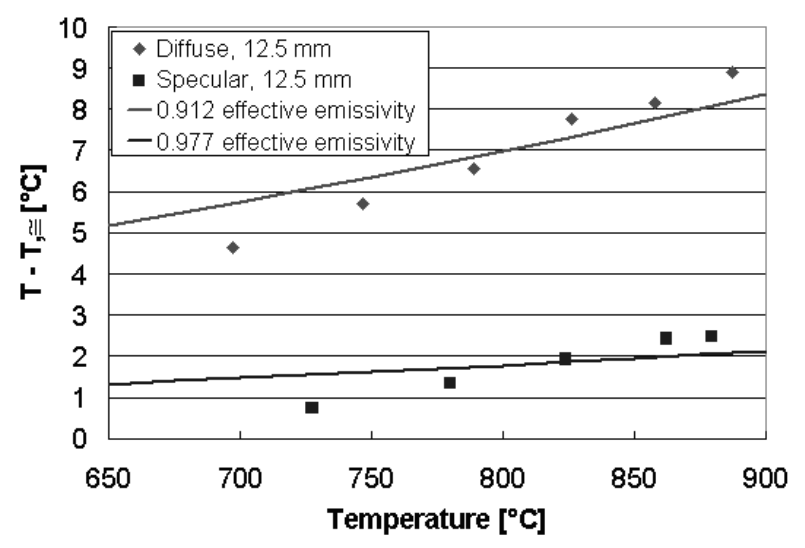

Fig. 17. Values of $T_{\mathrm{tc}}-T_{\lambda}$ near wafer center.
0.799), implying a larger $\varepsilon_{\text {eff }}$ for the specular shield. For both shields, the temperature accuracy of the LPRT will be improved by in situ calibration. By curve fitting, the $\varepsilon_{\text {eff }}$ for the specular and diffuse shields were estimated to be 0.98 and 0.91 , respectively.

Figure 18 shows the effects on $T_{\mathrm{tc}}-T_{\lambda}$ of changing the wafer/shield spacing. For this plot, the specular shield was used. While the results for spacings of $12.5 \mathrm{~mm}$ and $15.5 \mathrm{~mm}$ are identical to within the resolution of the measurements, the values for $T_{\mathrm{tc}}-T_{\lambda}$ increase as the spacing is decreased from $12.5 \mathrm{~mm}$ to $6 \mathrm{~mm}$. This effect can be explained by the optical perturbation on $\varepsilon_{\text {eff }}$ of the LPRT target area caused by the presence of the LP, which has a much smaller

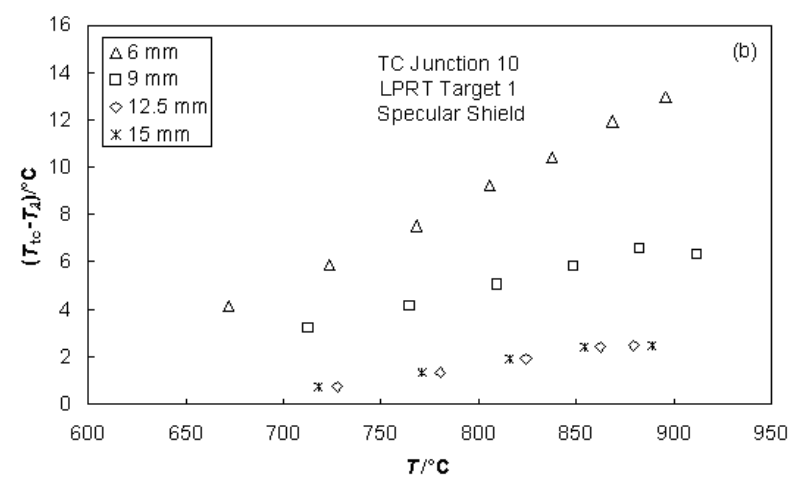

Fig. 18. Values of $T_{\mathrm{tc}}-T_{\lambda}$ near wafer center for four different wafer/shield spacings. 
reflectance $(\rho=0.075)$ than the shield. Because the LP occupies a large solid angle of the field-of-view as seen from a point on the wafer when the wafer is close to the shield, an in situ calibration should be performed with the same spacing as in the application.

\subsection{Uncertainties}

According to Table 6, the dominant uncertainty of $2.0^{\circ} \mathrm{C}$ for the in situ LPRT calibration arises from the physical separation of $1.4 \mathrm{~cm}$ between the TFTC junctions and the center of the LPRT target and is based on the assumption of a uniform temperature gradient of $10{ }^{\circ} \mathrm{C}$ in this separation [22,25]. However, no correction for temperature gradients was ever applied to the calibration measurements. Other measurement uncertainties include thermocouple calibration uncertainties, from temperature fluctuations and long-term temperature drift of the wafer while in steady state, LPRT calibration uncertainties, and instrument uncertainties for temperature measurement with the thermocouples and LPRTs. The standard uncertainty for the in situ LPRT calibration is $2.3{ }^{\circ} \mathrm{C}$.

Table 6. Measurement uncertainties for in situ LPRT calibration

\begin{tabular}{lc}
\hline \multicolumn{1}{c}{ Component } & $U /{ }^{\circ} \mathrm{C}$ \\
\hline TFTC calibrations & 0.4 \\
Thermocouple emf measurements & 1.0 \\
LPRT calibrations & 0.2 \\
LPRT measurements & 0.1 \\
Wafer temperature fluctuations & 0.4 \\
Wafer Temperature drift & 0.1 \\
Junction/target temperature difference & 2.0 \\
\hline \multirow{2}{*}{ Total } & 2.3 \\
\hline
\end{tabular}

\section{Effective Emissivity Models}

To establish the uncertainty of LPRT measurements for wafer temperature, it was necessary to develop models for estimating the effective emissivity of the wafer that include effects due to wafer emissivity, shield reflectivity, lightpipe (LP) sensing tip area, and guard surface geometry and their radiative properties. Comparison of the TC and model-corrected LPRT temperature measurements are presented and the uncertainties of the LPRT calibration are described. Measurements of the room-temperature, directionalhemispherical reflectance for the RTP chamber reflective shields and the silicon wafer in Fig. 19 were obtained using the NIST Spectral Tri-function Automated Reference Reflectometer (STARR) [75] and were used to determine shield emissivities. The room temperature spectral reflectance at $\lambda=0.955 \mu \mathrm{m}$ for the silicon wafers used in our study was measured as 0.686 , which is in close agreement with the database [76] value at $30^{\circ} \mathrm{C}$ of 0.680 from which the high temperature emissivity values were estimated.

\subsection{Wafer-Chamber Arrangement: the Radiation Enclosure}

The simplest model for predicting the wafer effective emissivity represents the wafer-shield as a two-surface (infinite-parallel planes) enclosure. If the separation gap between the wafer-shield is very small, and there are no appreciable temperature gradients across the wafer, this model is appropriate. However, this model cannot account for the effects caused by the presence of the cold (nearly black) sensing tip of the LP [16]. Figure 19 illustrates a more realistic model representing the wafer-chamber configuration by five regions: 1 ) the $4.3 \mathrm{~mm}$ diameter LP with $2.5 \mathrm{~mm}$ diameter tip, located

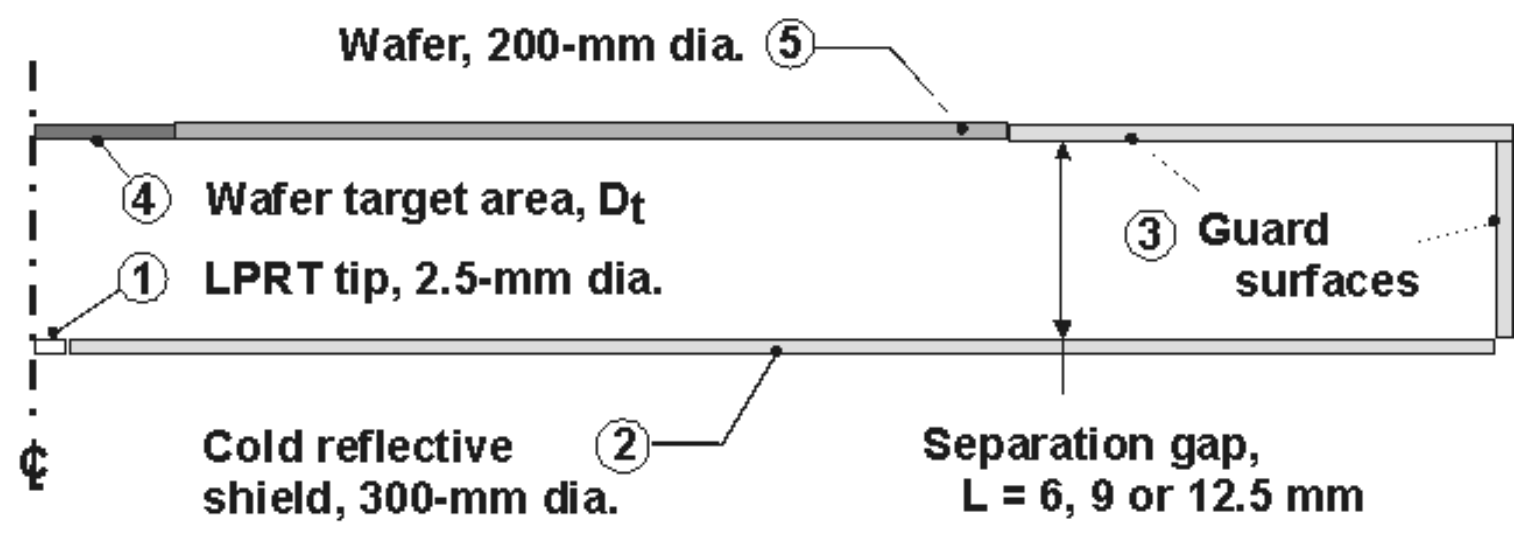

Fig. 19. Cross-section schematic of the classical diffuse/specular enclosure. 
in the center of the cold reflective shield having a reflectance of $0.0754,2$ ) the $300 \mathrm{~mm}$ diameter reflective shield, which is cold and diffuse or specular, 3) the lateral surface cold wall, which surrounds the wafer and the reflective shield, and which has a gap separation of $L$ and an emissivity of unity, 4) the LP field-ofview (target) at the wafer center of a diameter determined by the LP field-of-view and gap separation, and 5) the remaining surface of the $200 \mathrm{~mm}$ silicon wafer, but not including the LP target. Classical gray, diffuse or specular, enclosure analyses have been performed for this configuration using 24 zones. Since the wafer is assumed isothermal with an emissivity of 0.65 and all other surfaces are assumed cold, the effective emissivity is independent of the wafer temperature and depends only upon the chamber geometry and radiative properties of the enclosure surfaces.

\subsection{Types of Models}

Two models are described for estimating the wafer effective emissivity for the five-zone enclosure shown in Fig. 19. The first model treats the reflective shield as diffuse; that is, for a diffuse-gray enclosure. The second model treats the reflective shield as specular, while the remaining surfaces in the enclosure are diffuse.

\subsubsection{Model With the Diffuse Shield}

Using the temperature measurement equation with the estimated effective emissivity $\varepsilon_{\text {eff }}$, an estimate of the wafer temperature $T$ can be determined from the observed spectral radiance temperature $T_{\lambda}$,

$$
\frac{1}{T}=\frac{1}{T_{\lambda}}+\frac{\lambda}{c_{2}} \ln \varepsilon_{\text {eff }},
$$

where $\lambda$ is the operating wavelength of the radiation thermometer and $c_{2}$ is the second radiation constant, $14,387.752 \mu \mathrm{m} \times \mathrm{K}$. For the diffuse shield, the enclosure model is developed using the classical, radiosity method $[39,77]$ in which a radiation energy balance is written for each surface (zone) $A_{i}$ of the $N$-zone enclosure of the form,

$$
\sum_{j=1}^{N}\left[\delta_{i j}-\left(1-\varepsilon_{i}\right) F_{i-j}\right] J_{j}=\varepsilon_{i} E_{\mathrm{b} i}
$$

where $\delta_{i j}$ is the Kronecker delta function, $E_{\mathrm{b} i}$ is the blackbody emissivity power, $\varepsilon_{i}$ is the emissivity, $J_{i}$ is the radiosity, and $F_{i-j}$ is the diffuse radiation view (or exchange) factor defined as the ratio of radiation leaving an emitting surface $A_{i}$ to the reflected irradiation that is intercepted by a receiving surface $A_{j}$. Using appropriate temperatures, emissivities and the $N^{2}$ view factors, the system of $N$ equations is solved simultaneously to obtain the radiosities. The radiosity $J_{i}$ represents the diffuse radiation leaving the surface $A_{i}$ due to direct emission and reflected irradiation resulting from intereflections within the enclosure. The effective emissivity $\varepsilon_{\text {eff }}$ of the target area (t),

$$
\varepsilon_{\text {eff }}=\frac{J_{\mathrm{t}}}{E_{\mathrm{b}, \mathrm{t}}}=\frac{J_{\mathrm{t}}}{\sigma T_{\mathrm{t}}^{4}}
$$

is defined as the ratio of the target radiosity, $J_{t}$, to the blackbody emissive power, $E_{\mathrm{b}, \mathrm{t}}$ at the temperature, $T_{\mathrm{t}}$, of the target area, where the Stefan-Boltzmann constant $\sigma$ is $5.67051 \times 10^{-8} \mathrm{~W} /\left(\mathrm{m}^{2} \times \mathrm{K}^{4}\right)$. Since the surfaces are gray, the total and spectral effective emissivities are equal, and this value is used in the temperature measurement equation, Eq. (1), to determine the wafer temperature from the measured spectral radiance temperature.

\subsubsection{Model with the Specular Shield}

For the specular shield, we have implemented the classical radiation transfer enclosure analysis for specular and diffuse surfaces [77]. In our model, all $N$ surfaces of the enclosure emit diffusely, but the $d$ diffuse surfaces $(i=1,2, \ldots, d$; wafer and guard surfaces or zones) reflect diffusely and the $(N-d)$ specular surfaces $(i=d+1, d+2, \ldots, N$; the shield surfaces or zones) reflect specularly. For each diffuse surface, the radiation leaving the surface by direct emission and reflected irradiation is diffuse and is represented by the radiosity, $J_{i}$. For each specular surface, the only diffuse radiation leaving the surface is by emission, $\varepsilon_{i} E_{\mathrm{b} i}$; the incident irradiation is specularly reflected. The transport between the surfaces based upon the radiosities $J_{i}$ and emissive powers $E_{\mathrm{b} i}$ is determined by the specular exchange factor $F_{i-j}^{\mathrm{s}}$, defined as the fraction of diffuse radiation leaving $A_{i}$ that is intercepted by $A_{j}$ by the direct path and by all possible paths involving intermediate specular reflections. Since the shield is planar and is the only specular surface in the enclosure aside from the direct path, there is just one additional path (no multiple specular reflections), thereby simplifying the evaluation of $F_{i j \mathrm{~s}}^{\mathrm{s}}$. The energy balances for each of the diffuse surfaces forms a system of $d$ equations that must be solved to determine the radiosity of the target area,

$$
\begin{aligned}
& \sum_{j=1}^{N}\left[\delta_{i j}-\left(1-\varepsilon_{i}\right) F_{i-j}^{\mathrm{s}}\right] J_{j}=\varepsilon_{i} E_{\mathrm{b} i} \\
& +\left(1-\varepsilon_{i}\right) \sum_{j=d+1}^{N} \varepsilon_{j} E_{\mathrm{b} j} F_{i-j}^{\mathrm{s}} .
\end{aligned}
$$


The effective emissivity of the wafer target follows from Eq. (3) as with the diffuse case. Again, Eq. (1) is used to determine the model-corrected LPRT temperature. The radiation balances, Eqs. (2) and (4), for the enclosures with the diffuse and specular shield, respectively, were solved using 24 zones to represent the five regions earlier identified. Each zone is characterized by an area of uniform temperature and emissivity (or reflectivity). The wafer was represented by 10 concentric zones and the shield by 12 concentric zones. The guard ring and the guard tube were each represented by one zone. The resulting system of equations, with one equation for each radiation balance, was solved numerically for the radiosity $J_{i}$ of each surface by using a standard LU decomposition method [78].

\subsection{Discussion of Results}

A parametric study with the two enclosure models showed how the wafer effective emissivity is affected by wafer and shield radiative properties, gap separation, and LP sensing tip area. In Fig. 20, the diffuseenclosure model shows the effective emissivity as a function of gap separation when the LP sensing tip has the shield reflectance (top set of curves) compared to conditions with a black tip. For the black LP tip condition, as $L$ approaches $0 \mathrm{~mm}, \varepsilon_{\text {eff }}$ approaches the wafer emissivity. For large gap separations, the influence of the LP tip radiative properties has minimal effect. At $L=12.5 \mathrm{~mm}$, the LP tip condition has little influence (less than 0.01 emissivity units or $0.7 \mathrm{~K}$ ) on the diffusemodel prediction for the effective emissivity. In Fig. 21, the effective emissivity results are based upon the diffuse model, assuming black LP tip areas of different diameters, for shields with reflectance of $99.3 \%$ (specular) and $79.9 \%$ (diffuse). At $L=12.5 \mathrm{~mm}$, doubling the LP tip diameter from the 4-mm diameter, representative of the experiment conditions, to $8-\mathrm{mm}$ diameter, reduces the effective emissivity by 0.016 and 0.012 for the $99.3 \%$ shield and $79.9 \%$ shield, respectively. These emissivity changes amount to temperature changes of $0.9 \mathrm{~K}$ and $1.2 \mathrm{~K}$, respectively.

The results from the modeling analyses are summarized in Fig. 22 and compared against the experimental effective emissivity values based upon a best fit with the TFTC measurements. The effective emissivity is shown as a function of the gap separation for chamber configurations with diffuse (79.9\% reflectance) and specular $(99.3 \%)$ shields. In the limits for very small gap separations, the effective emissivity approaches 0.65 , the emissivity of the wafer. At larger gap separations, the effect of shield diffuseness or specularity is less than for smaller gaps. The data points for gap separations of $6 \mathrm{~mm}, 9 \mathrm{~mm}$, and $12.5 \mathrm{~mm}$, represent the effective emissivity value that provides the best fit between the TFTC measurements and the corrected LPRT measurement of true temperature. Clearly the trends of the data points and the model estimates with gap separation are in poor agreement. We expect the agreement to be poorest at very small gap separations

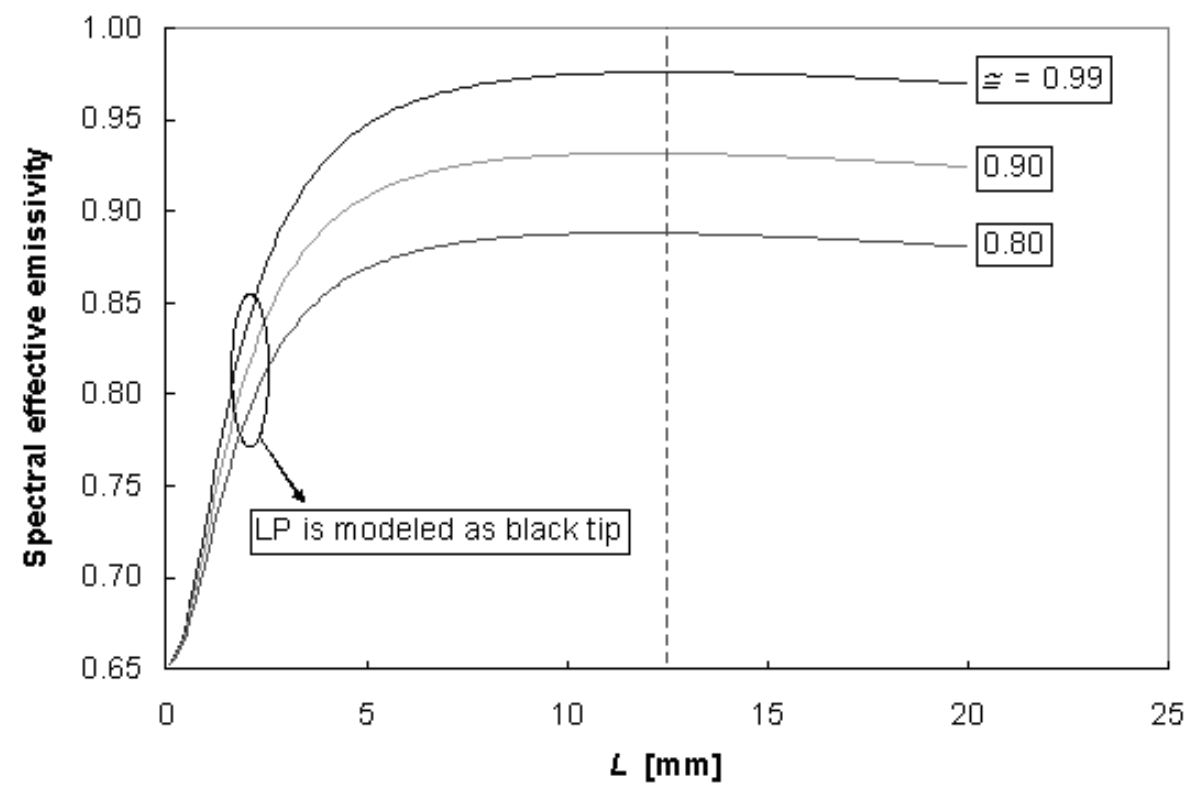

Fig. 20. Comparison of wafer effective emissivity for the LP tip with the shield reflectance ( 0.80 to 0.99$)$ vs a black LP tip. 


\section{Journal of Research of the National Institute of Standards and Technology}

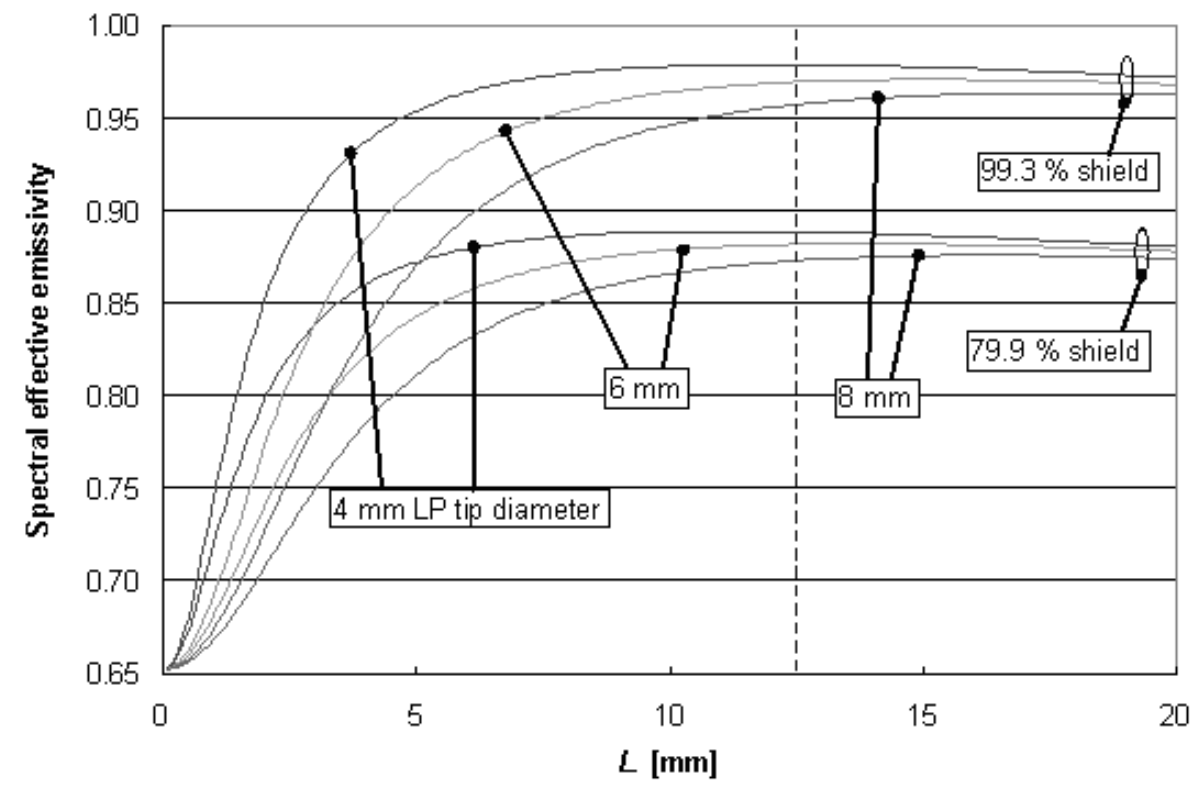

Fig. 21. Comparison of wafer effective emissivity predictions for different LP tip diameters.

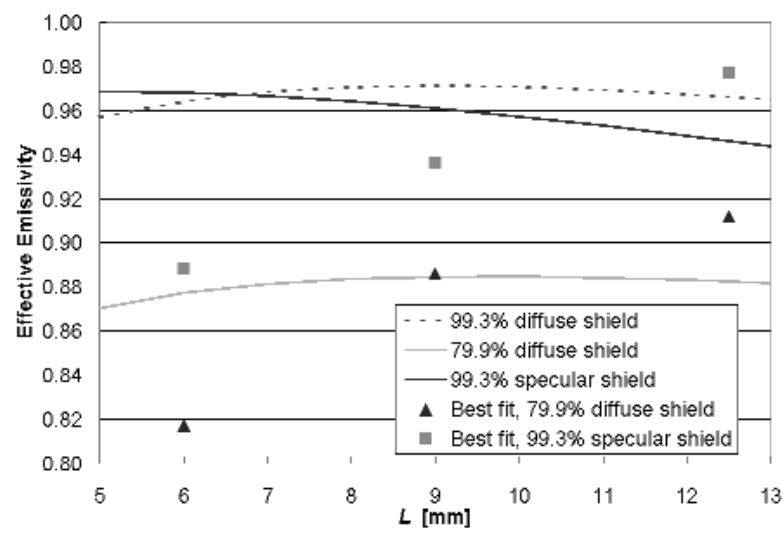

Fig. 22. Comparison of TFTC and model-corrected LPRT wafer temperatures (Trad).

since the interaction between the LP sensing tip and wafer target become increasingly more complicated. Full confidence in the radiation modeling cannot be established until the gap-separation trends and the effects of shield diffuseness are understood.

\subsection{Uncertainty Analysis}

Estimates of the uncertainties from the LPRT and TC measurements are shown in Table 8. A major contributor to the LPRT measurement uncertainty is the effective emissivity uncertainty of about $3.0^{\circ} \mathrm{C}$. The uncertainty due to the difference between the LPRT target and the TFTC junctions is $2.0^{\circ} \mathrm{C}$. Most of the TC total uncertainty is due to the TFTC uncertainty based on the large $\left(10^{\circ} \mathrm{C}\right)$ difference across the $80 \mathrm{~mm}$ length of the TFTC. The total LPRT and TC measurement uncertainties are $3.5^{\circ} \mathrm{C}$ and $0.3{ }^{\circ} \mathrm{C}$, respectively. From this analysis we conclude that it would be possible to calibrate the LPRT for spectral radiance temperature within $0.5^{\circ} \mathrm{C}$ and for actual thermodynamic temperature within $3.5^{\circ} \mathrm{C}$.

Table 8. Temperature uncertainties $\left[{ }^{\circ} \mathrm{C}\right]$ for comparison of LPRT and TC measurements

\begin{tabular}{llll}
\hline \hline \multicolumn{1}{c}{ LPRT measurements } & & \multicolumn{2}{c}{ TC measurements } \\
\hline Calibration & 0.2 & TFTC $\left(10{ }^{\circ} \mathrm{C}\right)$ & 0.3 \\
Effective emissivity & 3.0 & Pd/Pt TC & 0.1 \\
Junction/target temperature difference & 2.0 & TC emf & 0.1 \\
Temperature fluctuations & 0.4 & & \\
Temperature drift & 0.1 & & \\
LPRT display & 0.1 & & \\
\hline Subtotal & 3.5 & Subtotal & 0.3 \\
\hline
\end{tabular}

\section{Conclusions and Future Work}

We have demonstrated that LPRTs can be calibrated at NIST against a stable blackbody with a standard uncertainty of $0.3{ }^{\circ} \mathrm{C}$, that calibrated LPRTs can be compared against TFTC wafers with an uncertainty of 
$2.1^{\circ} \mathrm{C}$, and that calibrated LPRTs can be used with model-based algorithms to determine the wafer temperature with an uncertainty of $3.5^{\circ} \mathrm{C}$. A hallmark of the LPRT research at NIST has been the thorough effort of establishing proper calibration and characterization procedures for LPRTs and making critical recommendations for effective LPRT usage protocols. We have stressed the importance of traceability and uncertainty analysis to the RTP community. The utility of models was shown to assist in uncertainty analysis, prediction of properties for chamber design, and achievement of our temperature goals.

For future work, emissivity compensated reflectometer measurements could be a viable alternative for temperature measurements in semiconductor systems. The emittance initiative at NIST has motivated the development of a facility to characterize the emittance of samples as a function of temperature and wavelength. This could prove critical for the semiconductor industry in making more accurate LPRT temperature measurements. The new-generation CLRTs should be investigated as a diagnostic and measurement tool for temperatures up to $900{ }^{\circ} \mathrm{C}$. In particular, CLRTs in the infrared region will be useful for post-exposure bake and other applications in the temperature range from $25^{\circ} \mathrm{C}$ to $200^{\circ} \mathrm{C}$.

\section{Acknowledgments}

The author gratefully acknowledges David W. Allen and Dr. Kenneth G. Kreider for their careful review and valuable comments in the writing of this manuscript. Many staff members at NIST have contributed directly to the research aspects of the RTP Temperature Project (Dr. Thomas R. O'Brian, Dr. David P. DeWitt, Dr. Kenneth G. Kreider, David W. Allen, Dr. Christopher W. Meyer, Dr. Francis J. Lovas, Vincent P. Scheuerman, Dr. Murthy V. Annageri, William A. Kimes) and indirectly by support of management (Robert D. Saunders, Billy W. Mangum, Dean C. Ripple, Gerald T. Fraser, Dr. Edward A. Early, Albert C. Parr, James R. Whetstone, Gregory J. Rosasco, and others) and from the Office of Microelectronics Programs (Robert I. Scace, Dr. Stephen Knight, and Dr. Joaquin V. Martinez de Pinillos). Dr. Zhuomin Zhang and his colleagues (Mr. Ferdinand Rosa, Dr. Donghai Chen, Dr. Yihui Zhou, Dr. Yu-Jiun Shen, and Mr. Bong Jae Lee) performed much of the modeling work. Finally, this paper is a tribute to Dr. David P. DeWitt, my teacher, mentor, colleague, and friend, who recently passed away.

\section{References}

[1] SIA, International Technology Roadmap for Semiconductors, http://public.itrs.net/ (1997-2004).

[2] NIST, http://www.nist.gov/public_affairs/nist_mission.htm (2002).

[3] H. Preston-Thomas, The International Temperature Scale of 1990 (ITS-90), Metrologia 27, 3-10 (1990).

[4] R. R. Dils, High Temperature Optical Fiber Thermometer, J. Appl. Phys. 54, 1198-1201 (1983).

[5] R. R. Dils, Measurement of the Silver Freezing Point with an Optical Fiber Thermometer: Proof of Concept, J. Appl. Phys. 59, 1005 (1986).

[6] J. C. Richmond and D. P. DeWitt, Applications of Radiation Thermometry, ASTM STP 895, (1985).

[7] C. Schietinger, B. Adams, and C. Yarling, Ripple Technique: A Novel Non-Contact Wafer Emissivity and Temperature Method for RTP, in Mat. Res. Soc. Symp. Proc., Vol. 224, Rap. Therm. Integ. Proc., J. C. Gelpey, M. L. Green, R. Singh, and J. J. Wortman, eds., MRS, Pittsburgh (1991) pp. 23-31.

[8] B. E. Adams, The Challenges of Temperature Measurement in the Semiconductor Industry, in Proc. TEMPMEKO '99, Vol. 1, The 7th Intl. Symp. Temp. Therm. Meas., Edauw \& Johannissen, Delft, J. F. Dubbeldam and M. J. de Groot, eds. (1999) pp. 3-10.

[9] A. T. Fiory, Rapid Thermal Annealing and Oxidation of Silicon Wafers with Backside Films, in Mat. Res. Soc. Symp. Proc., Vol. 470, Rap. Therm. Integ. Proc. VI, T. J. Riley, J. C. Gelpey, F. Roozeboom, and S. Saito, eds., MRS, Pittsburgh (1997) pp. 49-56.

[10] G. C. Xing, Z. H. Wang, C. Schietinger, Y. Wasserman, and M. H. Sun, Application of Ripple Pyrometry on Integra Rapid Thermal CVD Cluster Tools, in Mat. Res. Soc. Symp. Proc., Vol. 387, S. R. J. Brueck, J. C. Gelpey, A. Kermani, J. L. Regolini, and J. C. Sturm, eds. (1995) pp. 119-124.

[11] J. P. Hebb and C. Schietinger, In Situ Wafer Emissivity Measurements in a Furnace Heated RTP System, in Proc. RTP '97, 5th Intl. Conf. Adv. Therm. Proc. Semic., R. B. Fair, M. L. Green, B. Lojek, and R. P. S. Thakur, eds. (1997) pp. 203-211.

[12] D. P. DeWitt, F. Y. Sorrell, and J. K. Elliott, Temperature Measurement Issues in Rapid Thermal Processing, in Mat. Res. Soc. Symp. Proc., Vol. 470, Rap. Therm. Integ. Proc. VI, T. J. Riley, J. C. Gelpey, F. Roozeboom, and S. Saito, eds., MRS, Pittsburgh (1997) pp. 3-15.

[13] K. G. Kreider and F. DiMeo, Platinum-palladium thin-film thermocouples for temperature measurement on silicon wafers, in Proc. RTP '97, 5th Intl. Conf. Adv. Therm. Proc. Semic., R. B. Fair, M. L. Green, B. Lojek, and R. P. S. Thakur, eds. (1997) pp. 105-113.

[14] A. W. Ruff and K. G. Kreider, Deposited thin-film wear sensors: materials and design, Wear 203-204, 187-195 (1997).

[15] B. K. Tsai, F. J. Lovas, D. P. DeWitt, K. G. Kreider, G. W. Burns, and D. W. Allen, In-Chamber Calibration using a Silicon ProofWafer, in Proc. RTP '97, 5th Intl. Conf. Adv. Therm. Proc. Semic., R. B. Fair, M. L. Green, B. Lojek, and R. P. S. Thakur, eds. (1997) pp. 340-346.

[16] K. G. Kreider, D. P. DeWitt, B. K. Tsai, F. J. Lovas, and D. W. Allen, Calibration Wafer for Temperature Measurements in RTP Tools, in Char. Metr. ULSI Tech., Vol. 449, D. G. Seiler, A. C. Diebold, W. M. Bullis, T. J. Shaffner, R. McDonald, and E. J. Walters, eds., American Institute of Physics, Woodbury, NY (1998) pp. 303-309. 
[17] K. G. Kreider, D. P. DeWitt, B. K. Tsai, F. J. Lovas, and D. W. Allen, RTP Calibration Wafer using Thin-Film Thermocouples, in Mat. Res. Soc. Symp. Proc., Vol. 525, Rap. Therm. Integ. Proc. VII, M. C. Öztürk, F. Roozeboom, P. J. Timans, and S. H. Pas, eds., MRS, Pittsburgh (1998) pp. 87-94.

[18] K. G. Kreider and F. DiMeo, Platinum-Palladium Thin-Film Thermocouples for Temperature Measurement on Silicon Wafers, Sensors Actuators A69, 46-52 (1998).

[19] K. G. Kreider, D. C. Ripple, and D. P. DeWitt, Determination of the Seebeck Coefficient of Thin Films, in Proc. 44th Intl. Instr. Symp., P. McCarty, ed., ISA, Research Triangle Park, NC (1999) pp. 561-570.

[20] K. G. Kreider, D. C. Ripple, and D. P. DeWitt, Calibration of Thin-Film Thermocouples on Silicon Wafers, in Proc. TEMPMEKO '99, Vol. 1, The 7th Intl. Symp. Temp. Therm. Meas., Edauw \& Johannissen, Delft, J. F. Dubbeldam and M. J. de Groot, eds. (1999) pp. 286-291.

[21] K. G. Kreider and G. Gillen, Thin-Film Calibration Wafer Materials for RTP Temperature Measurement, in Proc. RTP '99, 7th Intl. Conf. Adv. Therm. Proc. Semic., H. Kitayama, B. Lojek, G. Miner, and A. Tillman, eds. (1999) pp. 142-147.

[22] C. W. Meyer, D. W. Allen, D. P. DeWitt, K. G. Kreider, F. J. Lovas, and B. K. Tsai, ITS-90 Calibration of Radiometers using Wire/Thin-Film Thermocouples in the NIST RTP Tool: Experimental Procedures and Results, in Proc. RTP '99, 7th Intl. Conf. Adv. Therm. Proc. Semic., H. Kitayama, B. Lojek, G. Miner, and A. Tillman, eds. (1999) pp. 136-141.

[23] B. K. Tsai, D. P. DeWitt, F. J. Lovas, K. G. Kreider, C. W. Meyer, and D. W. Allen, Chamber Radiation Effects on Calibration of Radiation Thermometers with a Thin-Film Thermocouple Test Wafer, in Proc. TEMPMEKO '99, Vol. 1, The 7th Intl. Symp. Temp. Therm. Meas., Edauw \& Johannissen, Delft, J. F. Dubbeldam and M. J. de Groot, eds. (1999) pp. 726-731.

[24] K. G. Kreider, Temperature calibration Wafer for Rapid Thermal Processing using Thin-film Thermocouples, U.S. Patent $6,037,645(2000)$.

[25] K. G. Kreider, D. P. DeWitt, C. W. Meyer, and V. P. Scheuerman, Calibration of Lightpipe Radiation Thermometers in a RTP Tool at $1000^{\circ} \mathrm{C}$, in Proc. RTP 2000, 8th Intl. Conf. Adv. Therm. Proc. Semic., D. P. DeWitt, J. Kowalski, B. Lojek, and A. Tillman, eds. (2000) pp. 65-70.

[26] K. G. Kreider and G. J. Gillen, High Temperature materials for thin-film thermocouples on silicon wafers, Thin Solid Films 376, 32-37 (2000).

[27] C. W. Meyer, D. P. DeWitt, K. G. Kreider, F. J. Lovas, and B. K. Tsai, ITS-90 Calibration of Radiation Thermometers for RTP Using Wire/thin-film Thermocouples on a Wafer, in Char. Metr. ULSI Tech., Vol. 550, D. G. Seiler, A. C. Diebold, T. J. Shaffner, R. McDonald, W. M. Bullis, P. J. Smith, and E. M. Secula, eds., American Institute of Physics, Woodbury, NY (2000) pp. 254258.

[28] K. G. Kreider, D. P. DeWitt, and B. K. Tsai, Workshop on Temperature Measurement of Semiconductor Wafers Using Thermocouples, NISTIR 6566 (2001).

[29] K. G. Kreider, W. A. Kimes, C. W. Meyer, D. C. Ripple, B. K. Tsai, D. H. Chen, and D. P. DeWitt, Calibration of Radiation Thermometers in Rapid Thermal Processing Tools Using Si Wafers with Thin-film Thermocouples, in Proc. 8th Intl. Temp. Symp., Vol. 7, Temp.: Its Meas. Cont. Sci. Ind., D. C. Ripple, ed., AIP, Melville, NY (2003) pp. 1087-1092.

[30] W. A. Kimes, K. G. Kreider, D. C. Ripple, and B. K. Tsai, In Situ Calibration of Lightpipe Radiometers for Rapid Thermal
Processing between $300{ }^{\circ} \mathrm{C}$ to $700{ }^{\circ} \mathrm{C}$, in Proc. RTP 2004, 12th IEEE Intl. Conf. Adv. Therm. Proc. Semic., J. Gelpey, B. Lojek, Z. Nenyei, and R. Singh, eds. (2004) pp. 156-161.

[31] K. G. Kreider, D. P. DeWitt, J. B. Fowler, J. E. Proctor, W. A. Kimes, D. C. Ripple, and B. K. Tsai, Comparing the Transient Response of a Resistive-Type Sensor with a Thin-Film Thermocouple during the Post-Exposure Bake Process, in Data Analysis and Modeling for Process Control, in Proc. SPIE, Vol. 5378, K. W. Tobin, Jr., ed. (2004) pp. 81-92.

[32] F. J. Lovas, B. K. Tsai, and C. E. Gibson, Meeting RTP Temperature Accuracy Requirements: Measurement and Calibrations at NIST, in Mat. Res. Soc. Symp. Proc., Vol. 525, Rap. Therm. Integ. Proc. VII, M. C. Öztürk, F. Roozeboom, P. J. Timans, and S. H. Pas, eds., MRS, Pittsburgh (1998) pp. 127133.

[33] B. K. Tsai, C. W. Meyer, and F. J. Lovas, Characterization of Lightpipe Radiation Thermometers for The NIST Test Bed, in Proc. RTP 2000, 8th Intl. Conf. Adv. Therm. Proc. Semic., D. P. DeWitt, J. Kowalski, B. Lojek, and A. Tillman, eds. (2000) pp. 83-93.

[34] B. K. Tsai and D. P. DeWitt, Methods used at NIST to Characterize and Calibrate Lightpipe Radiation Thermometers, in Proc. TEMPMEKO 2001, Vol. 2, The 8th Intl. Symp. Temp. Therm. Meas., VDE Verlag GmbH, Berlin, B. Fellmuth, J. Seidel, and G. Scholz, eds., VDE Verlag, Berlin (2002) pp. 931936.

[35] B. K. Tsai and D. P. DeWitt, Characterization and Calibration of Lightpipe Radiation Thermometers for use in Rapid Thermal Processing, in Proc. 8th Intl. Temp. Symp., Vol. 7, Temp.: Its Meas. Cont. Sci. Ind., D. C. Ripple, ed., AIP, Melville, NY (2003) pp. 441-446.

[36] B. K. Tsai and D. P. DeWitt, Improving Temperature Accuracy for Rapid Thermal Processing at NIST, in the Proc. NCSLI 2002 Wkshp. Symp., San Diego, CA (2002).

[37] B. K. Tsai, Traceable Temperature Calibrations of Radiation Thermometers for Rapid Thermal Processing, in Proc. RTP 2003, 11th IEEE Intl. Conf. Adv. Therm. Proc. Semic., J. Gelpey, B. Lojek, Z. Nenyei, and R. Singh, eds. (2003) pp. 101106.

[38] F. Rosa, Y. H. Zhou, Z. M. Zhang, D. P. DeWitt, and B. K. Tsai, Modeling Chamber Radiation Effects on Radiometric Temperature Measurement in Rapid Thermal Processing, in Proc. 195th Mtg. Electroch. Soc., Vol. PV 99-10, Adv. RTP, F. Roozeboom, J. C. Gelpey, M. C. Ozturk, and J. Nakos, eds. (1999) pp. 419-426.

[39] B. K. Tsai and D. P. DeWitt, ITS-90 Calibration of Radiometers using Wire/Thin-Film Thermocouples in the NIST RTP Tool: Effective Emissivity Modeling, in Proc. RTP '99, 7th Intl. Conf. Adv. Therm. Proc. Semic., H. Kitayama, B. Lojek, G. Miner, and A. Tillman, eds. (1999) pp. 125-135.

[40] Y. J. Shen, Z. M. Zhang, B. K. Tsai, and D. P. DeWitt, Bidirectional Reflectance Distribution Function of Rough Silicon Wafers, in Proc. 14th Symp. Thermop. Prop., W. M. Haynes and R. A. Overfelt, eds. (2000).

[41] Y. H. Zhou, Y. J. Shen, and Z. M. Zhang, B. K. Tsai, and D. P. DeWitt, Impact of Directional Properties on the Radiometric Temperature Measurement in Rapid Thermal Processing, in Proc. RTP 2000, 8th Intl. Conf. Adv. Therm. Proc. Semic., D. P. DeWitt, J. Kowalski, B. Lojek, and A. Tillman, eds. (2000) pp. 94-103.

[42] Y. H. Zhou, Y. J. Shen, and Z. M. Zhang, B. K. Tsai, and D. P. DeWitt, Monte Carlo Simulation for Radiometric Temperature Measurement in Rapid Thermal Processing, in Proc. ASME HT 
Div. - 2000, HTD-Vol. 366-5, J. H. Kim et al., eds. (2000) pp. 187-190.

[43] K. G. Kreider, D. W. Allen, D. H. Chen, D. P. DeWitt, C. W. Meyer, and B. K. Tsai, Effects of Wafer Emissivity on Lightpipe Radiometry in RTP Tools, in Proc. RTP 2001, 9th Intl. Conf. Adv. Therm. Proc. Semic., D. P. DeWitt, J. Gelpey, B. Lojek, and Z. Nenyei, eds. (2001) pp. 163-168.

[44] Y. J. Shen, Z. M. Zhang, B. K. Tsai, and D. P. DeWitt, Bidirectional Reflectance Distribution Function of Rough Silicon Wafers, Intl. J. Thermophys. 22, 1311-1326 (2001).

[45] Y. H. Zhou, Y. J. Shen, Z. M. Zhang, B. K. Tsai, and D. P. DeWitt, A Monte Carlo model for predicting the effective emissivity of the silicon wafer in rapid thermal processing furnaces, Intl. J. Mass HT, 45, 1945-1949 (2001).

[46] Y. H. Zhou, Z. M. Zhang, D. P. DeWitt, and B. K. Tsai, Effects of Radiative Properties of Surfaces on Radiometric Temperature Measurement, in Proc. RTP 2001, 9th Intl. Conf. Adv. Therm. Proc. Semic., D. P. DeWitt, J. Gelpey, B. Lojek, and Z. Nenyei, eds. (2001) pp. 179-188.

[47] D. H. Chen, D. P. DeWitt, K. G. Kreider, B. K. Tsai, and W. A. Kimes, Effects of Wafer Emissivity on Rapid Thermal Processing Temperature Measurement, in Proc. RTP 2002, 10th Intl. Conf. Adv. Therm. Proc. Semic., J. Gelpey, B. Lojek, Z. Nenyei, and R. Singh., eds. (2002) pp. 59-67.

[48] D. H. Chen, D. P. DeWitt, B. K. Tsai, K. G. Kreider, and W. A. Kimes, Effects of Wafer Emissivity on Rapid Thermal Processing Temperature Measurement, in Proc. 8th Intl. Temp. Symp., Vol. 7, Temp.: Its Meas. Cont. Sci. Ind., D. C. Ripple, ed., AIP, Melville, NY, (2003) pp. 735-740.

[49] K. G. Kreider, D. P. DeWitt, D. H. Chen, W. A. Kimes, C. W. Meyer, and B. K. Tsai, Wafer Emissivity Effects on Light Pipe Radiometry in RTP Tools, in Proc. 201th Mtg. Electroch. Soc., Adv. Rap. Therm. Proc. Seattle, WA (2002) pp. 273-281.

[50] K. G. Kreider, D. H. Chen, D. P. DeWitt, W. A. Kimes, and B. K. Tsai, Effects of Lightpipe Proximity on $\mathrm{Si}$ Wafer Temperature in Rapid Thermal Processing Tools, in Char. Metr. ULSI Tech., Vol. 683, D. G. Seiler, A. C. Diebold, T. J. Shaffner, R. McDonald, S. Zollner, R. P. Khosla, and E. M. Secula, eds., American Institute of Physics, Woodbury, NY (2003) pp. 200204.

[51] K. G. Kreider, D. H. Chen, D. P. DeWitt, W. A. Kimes, and B. K. Tsai, Lightpipe Proximity Effects on Si Wafer Temperature in Rapid Thermal Processing Tools, in Proc. RTP 2003, 11th IEEE Intl. Conf. Adv. Therm. Proc. Semic., J. Gelpey, B. Lojek, Z. Nenyei, and R. Singh, eds. (2003) pp. 125-129.

[52] B. J. Lee, Z. M. Zhang, E. A. Early, D. P. DeWitt, and B. K. Tsai, Modeling the Radiative Properties of Silicon with ThinFilm Coatings and the Experimental Validation, in Proc. 37th AIAA Therm. Conf., Portland, OR (2004) pp. 167-172.

[53] B. K. Tsai, J. Bodycomb, D. P. DeWitt, K. G. Kreider, and W. A. Kimes, Emissivity Compensated Pyrometry for Specular Silicon Surfaces on the NIST RTP Test Bed, in Proc. RTP 2004, 12th IEEE Intl. Conf. Adv. Therm. Proc. Semic., J. Gelpey, B. Lojek, Z. Nenyei, and R. Singh, eds. (2004) pp. 167-172.

[54] B. K. Tsai, D. P. DeWitt, E. A. Early, L. M. Hanssen, K. G. Kreider, B. J. Lee, and Z. M. Zhang, Emissivity Standards for Improved Radiation Thermometry During Thermal Processing Of Silicon Materials, in Proc. TEMPMEKO 2004, The 9th Intl. Symp. Temp. Therm. Meas., D. Dvizdic, ed. (2004).

[55] D. P. DeWitt and G. D. Nutter, Theory and Practice of Radiation Thermometry, John Wiley \& Sons, Inc., New York (1988).
[56] American Society for Testing and Materials, Standard Test Methods for Radiation Thermometers (Single Waveband Type), E1256-95, 1995.

[57] American Society for Testing and Materials, Standard Test Method for Measuring Total-Radiance Temperature of Heated Surfaces Using a Radiation Pyrometer, E639-78, 1996.

[58] H. J. Kostkowski and R. D. Lee, Theory and Methods of Optical Pyrometry, NBS Monograph 41 (1962).

[59] D. R. Lovejoy, Recent Advances in Optical Pyrometry, in Proc. 4th Intl. Temp. Symp., Vol. 3, Temp.: Its Meas. Cont. Sci. Ind., C. M. Herzfeld, ed., AIP, Melville, NY (1962) p. 505.

[60] R. D. Lee, H. J. Kostkowski, T. J. Quinn, P. R. Chandler, T. N. Jones, J. Tapping, and H. Kunz, Intercomparison of the IPTS68 above $1064^{\circ} \mathrm{C}$ by Four National Laboratories, in Proc. 4th Intl. Temp. Symp., Vol. 4, Temp.: Its Meas. Cont. Sci. Ind., H. H. Plumb, ed., AIP, Melville, NY (1972) p. 377.

[61] J. C. Richmond and D. P. DeWitt, Application of Radiation Thermometry, ASTM, Philadelphia (1986).

[62] D. P. DeWitt, Advances and Challenges in Radiation Thermometry, in Proc. 10th Intl. HT Conf. Vol. 1 (1994) pp. 205-221.

[63] B. C. Johnson, C. E. Gibson, G. Machin, and R. L. Rusby, Intercomparison of the ITS-90 radiance temperature scales of the national physical laboratory and NIST, J. Res. Natl. Inst. Stand. Technol. 99, 731 (1994).

[64] B. C. Johnson, F. Sakuma, H. Sakate, C. E. Gibson, G. Machin, T. Ricolfi, M. Battuello, J. Fischer, and H. J. Jung, International comparison of radiation temperature scales among five national metrological laboratories using a transfer standard radiation thermometer, Metrologia 33, 241 (1996).

[65] C. E. Gibson, B. K. Tsai, and A. C. Parr, Radiance Temperature Calibrations, NIST Special Publication 250-43 (1998).

[66] Z. M. Zhang, Surface Temperature Measurement Using Optical Techniques, Ann. Rev. HT, 11, Begell House, Inc., New York (2000) pp. 350-411.

[67] B. N. Taylor and C. E. Kuyatt, Guidelines for Evaluating and Expressing the Uncertainty of the NIST Measurement Results, NIST Tech. Note 1297 (1994).

[68] NIST Calibration Services, NIST Calibration Services Users Guide, NIST Special Publication 250 (1998).

[69] NIST Calibration Services website, http://ts.nist.gov/ts/htdocs/ 230/233/calibrations/ (2003).

[70] T. C. Larason, S. S. Bruce, and A. C. Parr, Spectroradiometric Detector Measurements, NIST Special Publication 250-41 (1998).

[71] J. M. Houston and J. P. Rice, Versatility Performance Improvements Designed into a Cryogenic Radiometer, to be published in Metrologia (2006).

[72] T. R. Gentile, J. M. Houston, J. E. Hardis, C. L. Cromer, and A. C. Parr, The NIST High Accuracy Cryogenic Radiometer, Appl. Opt. 35, 1056 (1996).

[73] G. W. Burns and D. C. Ripple, Techniques for Fabricating and Annealing Pt/Pd Thermocouples for Accurate Measurements in the Range $0^{\circ} \mathrm{C}$ to $1300^{\circ} \mathrm{C}$, in Proc. TEMPMEKO '96, The 6th Intl. Symp. Temp. Therm. Meas., Levrotto \& Bella, Torino P. Marcarino, ed. (1997) pp. 171-176.

[74] G. W. Burns, D. C. Ripple, and M. Battuello, Platinum vs. Palladium Thermocouples: An Emf-Temperature Reference Function for the Range $0{ }^{\circ} \mathrm{C}$ to $1500{ }^{\circ} \mathrm{C}$, Metrologia 35, 761780 (1998).

[75] P. Y. Barnes, E. A. Early, and A. C. Parr, Spectral Reflectance, NIST Special Publication 250-48 (1998). 
Volume 111, Number 1, January-February 2006

\section{Journal of Research of the National Institute of Standards and Technology}

[76] J. P. Hebb, J. O. Cave, D. Wang, S. MacFarland, and K. F. Jensen, Multi-Rad software, Massachusetts Institute of Technology and International SEMATECH (1997).

[77] R. Siegel and J. R. Howell, Thermal Radiation Heat Transfer, Hemisphere Publishing Corporation, Washington (1992).

[78] W. H. Press, B. P. Flannery, S. A. Teukolsky, and W. T. Vettering, Numerical Recipes, Cambridge University Press, New York (1986).

[79] C. W. Meyer, Effects of Extraneous Radiation on the Performance of Lightpipe Radiation Thermometers, in Proc. TEMPMEKO 2001, Vol. 2, The 8th Intl. Symp. Temp. Therm. Meas., VDE Verlag GmbH, Berlin, B. Fellmuth, J. Seidel, and G. Scholz, eds., VDE Verlag, Berlin (2002) pp. 937-942.

About the author: Benjamin K. Tsai is a physical scientist in the Optical Technology Division of the NIST Physics Laboratory. The National Institute of Standards and Technology is an agency of the Technology Administration, U.S. Department of Commerce. 